\title{
Young Children \\ Learning About Maps At School and in the Neighbourhood
}

\section{by
Paulette Holland}

A thesis submitted in partial fulfilment of the requirements for the degree of Master of Education

Victoria University of Wellington

Te Whare Wananga o te Upoko o te Ika a Maui 


\begin{abstract}
In the New Zealand National Curriculum maps are defined as an essential skill along with graphs and tables. Despite the widespread use of maps in everyday life and their incorporation in more than one area of the curriculum there has been little research in New Zealand on children's knowledge of maps, their use and where and how children encounter them. The research reported in this thesis is an attempt to broaden our understanding of young school children's knowledge of maps and in particular the sources of their map knowledge in family, neighbourhood and school. The study was informed by two bodies of work, that of Fay Panckhurst on preschoolers' map knowledge and its sources, and the NEMP studies which assessed graphs, tables and maps at Years 4 and 8.
\end{abstract}

From a Decile 2 school, a sample of Year $3 \& 4$ children was selected before they had been introduced to maps at school. The students were interviews individually. Each was asked to select the maps from a collection, which included graphs and tables. The selection task showed that the students knew what maps were but had trouble recognising graphs or tables. The students then answered a set of questions about maps, and drew a map of New Zealand marking it on a number of locations. Over a period of three weeks their classroom teacher taught a unit on maps. The sample students were then interviewed again. While their original answers showed the influence of maps in homes and neighbourhood the classroom unit had provided them with technical knowledge and map language, and their maps of New Zealand improved in relation to shape, relationship of the islands, and knowledge of locations. It is argued that maps are not solely "skills" but as cultural artefacts they appear for example in works of literature, in games and on television and for migrant children they can provide links with countries of origin. 


\section{Acknowledgements}

I am grateful to the Board of Trustees and parents from the chosen school for consenting to my request for permission to carry out this study.

My thanks go to each of the children and the teachers who allowed me to interview and observe them for this study, sharing with me their understanding of mapping. In particular Kate Boyle who provided me with the insights into the learning experiences and reactions of her students.

My sincere thanks to my supervisor, Dr Geraldine McDonald, for her patience, support and guidance, as well as her timely advice and suggestions that helped me to map my way around this project.

I thank my colleagues for their professional support and interest in this study. Special thanks also to Dr Joanna Higgins for her support and suggestions. Thanks also to Linda Bonne for taking time to edit and provide ideas.

Thank you too to my family and friends, who were always there with their encouragement and practical support in order for me to complete this project. 


\section{Contents}

Abstract ii

Acknowledgements iii

Table of Contents iv

Tables and Figures vi

Chapter 1: Introduction 1

What is a Map? $\quad 2$

Sources of Map Knowledge 4

Summary 4

Chapter 2: Curriculum Documents and Assessment 5

Assessing Map Knowledge $\quad 7$

Discussion $\quad 8$

Summary $\quad 8$

Chapter 3: Review of Research about Maps and Learning 9

Characteristics of Maps $\quad 9$

Young Children and Maps 10

Process of Learning about Maps 11

Learning the use of Maps $\quad 12$

New Zealand Studies $\quad 13$

Learning and Teaching about Maps 14

$\begin{array}{ll}\text { Theories of Learning about Maps } & 17\end{array}$

Maps and Literature 18

$\begin{array}{ll}\text { Summary } & 19\end{array}$

Chapter 4: Method 20

Procedures $\quad 21$

Sample $\quad 22$

Interview Session $\quad 22$

The Classroom Unit on Maps $\quad 24$

Selection of Questions $\quad 24$

The Teacher $\quad 25$

Pilot Study $\quad 25$

Ethics $\quad 25$

Limitations of Study $\quad 26$

Summary 26

Chapter 5: Results: Selection Task 27

Summary $\quad 34$

Chapter 6: Results: Questionnaire 35

Summary 44

Chapter 7: Results: Drawing a Map of New Zealand 45

Student Responses $\quad 48$

Summary $\quad 49$ 
Chapter 8: Classroom Intervention $\quad 50$

Summary $\quad 54$

Chapter 9: Results: The Follow Up Interview 55

Discussion $\quad 59$

Summary $\quad 60$

Chapter 10: Results: Sketch Maps $\quad 62$

Student Responses $\quad 68$

Discussion $\quad 68$

Summary $\quad 69$

Chapter 11: Conclusion $\quad 70$

Discussion $\quad 77$

$\begin{array}{ll}\text { Postscript } & 77\end{array}$

References $\quad 79$

Appendices

Appendix A: Thesis Proposal 83

$\begin{array}{ll}\text { Appendix B: BOT letter } & 87\end{array}$

Appendix C: Parent Letter 88

Appendix D: First \& Second Interview Questions 90

Appendix E: Unit Overview $\quad 92$ 
Tables

Table 1:

Table 2:

Table 3:

Table 4:

Table 5:

Table 6:

Table 7:

Table 8:

Table 9:

Table 10:

\section{Figures}

Figure 1:

Figure 2:

Figure 3:

Figure 4:

Figure 5:

Figure 6:

Figure 7:

Figure 8:

Figure 9:

Figure 10:

Figure 11:

Figure 12:

Figure 13:

Figure 14:

Figure 15:

Figure 16:

Figure 17:

Figure 18:
Correct Selections for Tables, Maps and Graphs

Correct and Incorrect Selections for Tables, Maps and Graphs

33-34

Maps at Home $\quad 36$

Maps in the Car $\quad 37$

Atlas at Home or School 38

Initial Shape and Proportion of the Islands $\quad 47$

Initial Placement of Locations 48

Owning and Locating on an Atlas 58

Final Shape and Proportion of the Islands 67

Final Placement of Locations $\quad 67$

Mind Map 20

Coding Selection Items $\quad 27$

Tables $\quad 28$

Graphs $\quad 29$

Maps 30-31

Selections for Tables, Maps and Graphs 33

Student First Map Drawings $\quad$ 45-47

Collection of Maps for Using in the Classroom 50

Journal Article Map of Antarctica 52

Maps and Globes Used in the Classroom 53-54

Chris's Drawings $\quad 62$

Karl's Drawings 63

Natalie's Drawings 63

Sally's Drawings $\quad 64$

Roger's Drawings $\quad 64$

Trudy's Drawings $\quad 65$

Rachel's Drawings $\quad 65$

Liam's Drawings $\quad 66$ 


\section{CHAPTER 1}

\section{Introduction}

Maps are important in everyday life and being able to use a map is one of the information skills listed in The National Curriculum Framework (Ministry of Education, 1993) where they are associated with tables and graphs. I became interested in maps and children's understanding of them, through more than one source. In one of the classes for my master's degree, I had carried out a small study in which I asked my class of Year 2 children to draw a map of New Zealand and to locate some major features on it. The drawings came from students who had not had any formal teaching about maps and they showed a rather rudimentary understanding.

I also had some concern, shared by other teachers in my school, about students' general understanding of maps and their knowledge of locations in New Zealand. I had encountered children who did not understand that Auckland was not part of another country but part of New Zealand. I also thought that classroom teachers probably do not spend a lot of time teaching students about maps, assuming that students know what maps are and how to use them.

A further incentive to find out what young school children knew about maps was that little research on the topic had been carried out in New Zealand. Although the use of maps is so widespread in our society, surprisingly little research appears to have been carried out into children's understanding of maps and their ability to use them. The National Education Monitoring Project (NEMP) has tested children's understanding of maps in accordance with The Essential Information Skills (Nga Tino Pukenga) listed in The National Curriculum Framework (Ministry of Education, 1993, p. 17). There have been two reports from NEMP (Crooks \& Flockton, 1996, 2000) of results from a sample of Year 4 and Year 8 children. The commentaries in these reports, accompanying the map related items, do not suggest a high level of skill at Year 4, but show that skill levels had increased by Year 8 . The improvement in scores on the NEMP test items point to the role of teaching as the major influence on the outcomes. For example, there was an increase in accuracy of line graphs from Year 4 to Year 8 and it was noted that line graphs are "generally not taught until after Year 4" (Crooks \& Flockton, 2000, p. 4). If this was the result for line graphs then a similar effect from teaching can be assumed with regard to maps. 
We also have information about informal and environmental sources of learning such as floor maps in children's bedrooms or children's observations of route maps used by parents on car journeys (Panckhurst, 1989). In addition to this, there is information about the "language used by teachers and level-one children when they are learning about settings beyond New Zealand" (Hardie, 2002 p. 25). However, we know less about how to encourage map understanding and use.

The topic of my thesis arose for the reasons given above and because, as a practising teacher, I wanted to find out just what young students knew about maps and, if possible, to identify the sources of this knowledge in home, neighbourhood and classroom. This thesis addresses three broad questions.

1. What do young school children know about maps and their use?

2. Are young school children familiar with the map of New Zealand?

3. What do they gain from learning about maps in the classroom?

\section{What is a map?}

Maps are visual representations providing us with the "tools for discovering where things are, how things move and how regions change" (Robertson \& Gerber, 2000, p. 217). Maps mediate understanding of the environment and are so widespread that they can be considered as a cognitive tool, universal across cultures. Maps exist in great variety and can be found in sophisticated publications as well as on bark or cloth, or scratched in the earth or on rock.

Ultimately, the map presents us with the reality we know as differentiated from the reality we see. The map doesn't really let us see anything, it lets us know what others have seen or found or discovered. (Whitefield, 1997, p. 20)

Panckhurst, following Vygotsky (1978), defines maps as "cultural artefacts". "They have value and meanings, and they take a variety of form" (Panckhurst, 1989, p. 32). Like a system of writing, maps use specialised symbols for communicating the meaning of the spatial relationship of the physical world, and like writing, maps can be read. What maps represent can seldom be observed directly, and thus children need to understand what the culturally defined symbols, conventions, and layout mean in order to read a map successfully. 
While there are many kinds of maps, they fall into two major categories. Topographical maps represent geographical features and spatial relationships. They provide a scaled down version of the world, or a country or city. They may also be represented in different ways, of which the relief map, which indicates difference in elevation by shading, is a popular form. The other general kind of map is a route map used to show us where we are, where locations may be found, and how to get there. While a route map may be accurately represented in a scale model of territory, it may also be a hand drawn map showing "how to get to our place". Fantasy maps such as pirate maps showing the location of treasure can also be considered route maps. A map can be presented as a flat sheet or in the form of a globe. Students now have access to all kinds of maps. They are presented on the Internet; maps are commonly found in homes and communities; and maps may be found as illustrations in storybooks.

In the past there was not the luxury of computers and sophisticated measuring equipment. Today, with the aid of satellites, we are able to observe land formation from space. Technology is such that we can download a map using a cell phone. Satellite navigation systems can reproduce maps on screens in cars. We are exposed to daily reminders about maps and may unconsciously view these in many television programmes in addition to those reporting the news and weather. Programmes may show portions of maps relating to the area being discussed and occasionally a view of a whole country. Maps generally show much more than simple environmental facts. They may use colouring to represent political facts, and show boundaries of various kinds such as fishing zones.

Maps have a long history.

Map makers of the past based their images of the world on their own limited observations and on the reports of travellers returning from distant lands. Sometimes their ideas about the physical world were shaped by legends or religious beliefs. (Johnson, 1999, p. 4)

Even as early as the fifteenth century "hardly anyone could draw maps. This was partially due to limited instrumentation, but it was also due to the lack of common code for the representation of distance and special relations" (Haste, 1987, p.183). 


\section{Sources of map knowledge}

Before they have been taught formally about maps, young children learn from their observation of, and involvement in, activities which involve maps (Panckhurst, 1989). Nevertheless, young school children may have a limited knowledge of location and distance and, unless they have visited them, may have a restricted knowledge of where places are in their own cities, much less in their country and the world.

There are many things about maps which have to be learnt. What kind of map should we use? A route map designed for navigational purposes? These are often kept in cars and may appear on bus timetables displaying the route from point $A$ to point B. Or a relief map indicating high areas (mountains) and low areas (valleys), and features such as rivers, roads and bush, which will help us to understand the shape and pattern of the land.

Atlases put maps into one volume. The maps in atlases generally focus on the world, but some have specific sections dedicated to the country they are printed in, or they relate to a region of the world such as the Pacific. Places like libraries have atlases and so do most classrooms, but while many homes may have maps, atlases and globes are probably less common.

The study reported in this thesis was carried out in a school which has a substantial proportion of children whose families have migrated from the island nations of the Pacific. For these children maps can help them to make a link with their heritage.

\section{Summary}

This chapter has outlined the origins of my study. It has highlighted the limited amount of research into New Zealand children's understanding of maps and explained my original concern about a group of students' understanding about maps. The complexity of the topic was discussed in relation to the various types of maps, their uses and where they may be found. The next chapter reviews the place of maps in the New Zealand Curriculum. 


\section{CHAPTER 2}

\section{Curriculum Documents and Assessment}

Social Studies in the New Zealand Curriculum (Ministry of Education, 1997), Mathematics in the New Zealand Curriculum (Ministry of Education, 1992) and The New Zealand Curriculum Framework (Ministry of Education, 1993) outline the skills

and achievement objectives necessary for classroom teachers to implement the curriculum. The Curriculum Framework describes the essential elements and skills that students need to develop through the subjects of the curriculum. The Essential Skills, especially those of information and numeracy, outline minimum requirements for learning. Numeracy has the biggest link to mapping skills. Students need to "recognise, understand, analyse, and respond to information in graphs, maps, tables, charts, or percentages" (Ministry of Education, 1992, p. 18).

Of all the curriculum documents, Social Studies in the New Zealand Curriculum (Ministry of Education, 1997) deals most directly with maps. The current Social Studies curriculum (Ministry of Education, 1997) has five strands. The one which most represents mapping ability is the Place and Environment strand. This strand places more emphasis on understanding maps than on use of skills:

Importance of places and the environment to people and the ways in which people influence place and environment and are influenced by them. They will examine the different ways people and groups view places and environments and consider how and why people move between places and how places and environments change......Throughout this strand, students will learn how people record and describe the nature of places and environments. (Ministry of Education, 1997, p. 12)

This strand is also linked with three processes, Inquiry, Values Exploration and Social Decision Making which link with the Essential Skills (Ministry of Education, 1993).

The Social Studies curriculum provides opportunities for students to develop their knowledge and understanding about New Zealand. This includes studying "the location and significance of important natural and cultural features of the landscape" and "the physical environment of New Zealand and how people interact with the landscape" (Ministry of Education, 1997, p. 23). 
The Social Studies curriculum sets out what students should be learning at each level. The Achievement Objectives and indicators, in Place and Environment, at Level One state that:

Students will demonstrate knowledge and understanding of:

How and why people record the important features of places and environments. Students could demonstrate such knowledge and understandings when they describe ways in which people can record features of places and environments and describe how these people make use of different types of descriptions of places and environments.

(Ministry of Education, 1997, p. 38)

Level Two develops knowledge and understanding further by expecting students to:

Explain what place names reveal about places and environments:

Explain why people record descriptions of places and environments in different ways (e.g., through pictures, sound and video recordings, maps);

Explain why people choose to record particular features of places and environments. (Ministry of Education, 1997, p. 38)

These statements actually say little about map skills. They can be compared with the requirements of the National Curriculum for Geography in the United Kingdom:

By the end of Key Stage 2, children should be able to use and interpret globes, atlases and maps at a variety of scales and identify specified points of reference, including the continents. (Wiegand \& Stiell, 1996, p. 381)

Key Stage 2 is aimed at Year 3-6 students (7-11years).

Areas outlined in the curriculum documents are addressed by the Education Review Office (ERO) in their reviews of the quality of teaching in schools throughout New Zealand. During terms two and three in 2003, the Education Review Office spent time investigating the implementation and teaching of graphs, tables and maps in Years 4 and 8. Schools being reviewed during Term Four 2003 and Term One 2004 were involved in this process as part of Ministry of Education requirements. The process involved observations, questionnaires and interviews with teachers and 
students. In their report the Education Review Office states that "understanding and using information presented as graphs, tables or maps is an important part of everyday life in our community. Literacy in graphs, tables, and maps has application across several curriculum areas" (Education Review Office, 2004, p. 3).

\section{Assessing Map Knowledge}

Alongside the curriculum documents and the Education Review Office reports are the studies carried out by NEMP (New Zealand Education Monitoring Project). This project, which commenced in 1993, is designed to assess and report on the achievement of school children in all areas of the curriculum. Students are assessed at Year 4 and Year 8. A small, but random sample of students is selected from throughout New Zealand, to be part of this assessment. In 1997 and 2001 information was gathered on information skills and social studies. This included tasks that ascertained students' knowledge of the place they lived in. Results from the 1997 Social Studies report showed that about half of the year 4 students and 85 percent of year 8 students could place their home location on their own sketch map and that, "quite a high percentage of year 8 students showed that they were capable of reading, understanding and interpreting a basic topographical map" (Flockton \& Crooks, 1998, p. 35).

In 1995, 1999 and 2003, NEMP collected information on student's understanding of graphs, tables and maps (Crooks \& Flockton, 1996, 2000; Flockton \& Crooks, 2004). The report of the 2003 testing "highlights two aspects of the use of graphs, tables and maps: extracting and interpreting information, and constructing or completing graphs, tables and maps" (Flockton \& Crooks, 2004, p. 3). Their findings showed that "on average, students have made substantial progress between year 4 and year 8 in the skills assessed by the tasks" (p. 3). This was in both the interpretation of graphs, tables and maps and the construction or completion of the same items. Flockton and Crooks (2000) also analysed Maori performance in science, art, graphs, maps and tables.

New Zealand teachers also have another assessment tool to use to gather information about map skills. The Progressive Achievement: Test Study Skills, (Reid, Croft \& Jackson, 1978) was part of a series of tests (the PATs) specifically designed for use in New Zealand schools. They are: 
intended primarily to assist teachers in determining the levels of development attained by their pupils in the independent use of the many skills required in reading and interpreting different types of instructional and reference material at home, at school, and in the community. (Reid et al., 1978, p. 4)

NZCER has now replaced this test through inclusion in the Essential Skills Assessments (ESAs). In this, the information skills are:

Designed to help teachers assess a range of information skills that have classroom applications across a range of learning areas as defined in the New Zealand Curriculum Framework. (Croft, Dunn \& Brown, 2001, p. 1)

In this redesigned format, students are tested on graphs and tables in Module 2. Testing ability to use reference sources such as atlases and globes appears in Module 5.

\section{Discussion}

The emphasis in all curriculum documents and associated assessments is on mapping as one of a set of skills about the presentation and access of information, similar to the skills associated with tables and graphs. Maps are defined as a skill, which can be used across different curriculum areas. However, maps also have a broad social value and are in use across many areas of life. Maps can have artistic as well as utilitarian worth; they can be a source of pleasure as well as a repository of information.

\section{Summary}

This chapter has described the place of maps in the National Curriculum and has described the areas in each curriculum with which maps are linked. Links to the research carried out by NEMP and the assessment tools available to teachers from NZCER were also reported. 


\section{CHAPTER 3}

\section{Review of Research about Maps and Learning}

We can observe examples of maps in history dating back to the Greek mapmaker and geographer Claudius Ptolemaeus. Ptolemy, as he was known, studied geography and astronomy. He defined this as "a representation in pictures of the whole known world together with the parts contained therein" (Johnson, 1999, p. 6).

\section{Characteristics of maps}

The purpose of maps has moved over time from religious use, to road maps, sea charts and to atlases. Segall (2003) provides a cultural definition, likening maps to, "Perfectly transparent windows to physical and social reality. Like all media however, maps are not found objects but are created by humans" (p. 21). Segall describes maps as being:

A type of story, one told by a mapmaker. Using pictures, words, numbers, symbols, and icons, maps always simplify the world to provide a frame for understanding it. (Segall, 2003, p. 21)

Maps are intended to be selective and abstract representations of reality. Ellis (1998) contrasts the image of a map with that of a photograph. In photos, everything you see is seen by the eye of the camera. A map, however, "portrays only what is central to the message of the researcher" (p. 274). In a similar way, Whitefield sees maps as:

Like a language, maps are a pre-eminent means of recording and communicating information about the location and spatial characteristics of virtually every aspect of day-to-day life. (Whitefield, 1997, p. 21)

This is supported by Maceachren (cited in Whitefield, 1997) who implies that maps today are seen as "dynamic interactive spatial tools. This is in contrast with their more traditional role as static storage devices for spatial data" (p. 21). Welton and Mallan present a different interpretation describing the link, within social studies, between maps and globes as a tool: 
There is no question that maps, globes, and to a lesser extent, charts and tables are integral to social studies, yet there is nothing inherently "social" about any of them. They are simply specialized ways for presenting information. (Welton \& Mallan, 1996, p. 369)

\section{Young children and maps}

The suggestion that children of school-entering age cannot read and use maps, and cannot think about the world from a map-like, aerial perspective has been challenged by Sowden, Stea, Blades, Spencer and Blaut, (1996). Contrary to "Piaget's highly influential theory of cognitive development and particularly the Piagetian thesis that the spatial-cognitive abilities of so-called preoperational children - generally, children younger that seven - are not adequate for map reading and map use", Sowden et al. showed that "children as young as four years old have significant untaught mapping abilities" (Sowden et al., 1996, p. 107).

Children entering school have an ability, untaught, to read aerial photographs, to understand and use simple iconic maps of large environments. They can cope with very exciting concepts about geographically large environments, concepts that require the map perspective. They are ready (and eager) to learn geography. (Sowden et al.,1996, p. 110)

To understand something of the map understanding of young school children Maxim advises:

Watch a group of kindergartners or $1^{\text {st }}$-graders strive to create a neighbourhood with their blocks; they manoeuvre cars, buses and trucks up and down the streets, reacting to pedestrians and traffic signals or turning them into a service station or fill-up. Such active involvement, role-playing and mental exercise are key elements of a valuable early learning experience. Although these activities should emphasize creative play, not accuracy, the children are involved in making a symbolic representation of their actual environment. This, in essence is what maps are all about. (Maxim, 1997, p. 207)

One of the ways that children can develop perspective is by having opportunities to gain world experiences and build their map knowledge through observation. By 
observing their surroundings, seeing what the playground looks like, recalling and sharing details about their bedroom or classroom, they are able to build mental images that can later become maps. Swartz (2002) advocates using boxes and manipulatives to "create a town...to help the child gain the correct perspective" (p.64). Playing and building with blocks can also help to develop spatial ability and scale. Young children may act out stories about pirates and use treasure maps to find particular places.

Children also need to develop an understanding of perspective, but as Maxim (1997) suggests, they can do this by constructing miniature environments when playing with blocks, cars and trucks. Lenhoff and Huber (2000) support this and state that "as soon as children become mobile, they begin to explore spatial location" (p. 6).

Nevertheless maps can confuse young students. Rice (1990) points out that "for centuries, map makers have grappled with the problem of how to depict a round world on a flat surface" (p. 393). It is little wonder that children find it difficult to locate places on globes. Compare the image of New Zealand on a world map placed on the wall with its image on a globe.

\section{Processes of learning about maps}

The processes by which we learn about maps as objects can vary. Liben, Kastens and Stevenson (2002) suggest that:

One mechanism is via direct, real-world experience as we move within environments: travel from one location to another; and observe phenomena that persist or change over days, months, years, and locations. (Liben et al., 2002, p. 269)

Such influences shape a student's knowledge of their environment.

Overseas studies of maps have often been concerned with geography. Palmer, for example, stated that "early years geography is fundamentally about the development of the concepts of 'space' and 'place' and... a wide range of classroom tasks and related learning activities can contribute to effective learning of these concepts" (Palmer, 1994, p. 9). 
Another method is through the oral histories that many cultures impart over generations. Liben et al. note that:

Cultures record and communicate information about their near and distant worlds with representations as diverse as stick charts, woodcarvings, photographs, scale models and paper maps. (Liben et al., 2002, p. 269)

\section{Learning the use of maps}

In their description of person-space-map relations, Liben and Downs (1993) state that "understanding 'where you are' is a critical first step in using a map for route planning and route monitoring" (p. 739). Everyone carries images of maps with them in some form or another. How effective our images are depends on how often we use the maps. The map of a regular trip to the supermarket could instantly be brought to mind allowing us to make our way there or to tell someone else how to go there. Children are fascinated with the idea of having or using a treasure map. Perhaps not so much as using the map itself, but the excitement of finding "treasure" at the end. Students are required to use a number of skills to arrive at the treasure. They need knowledge in map reading, understanding symbols, using co-ordinates, following directions, spatial awareness, along with the skill of placing themselves on the map and moving from point to point. They also need to understand the notion of "birds eye view" and understand what it is like to look down on something. What becomes more difficult is having to recall images of maps we use less often, especially if we have not travelled the route or seen representations of the route in map form.

Children also need to know about the many differences there are in maps and the different kinds that are available. They see images of topographical, relief maps, route maps, weather maps, satellite maps, and they follow maps on many of the computer games they play.

By exposing children to a variety of maps, they can begin to develop map-reading skills. This is supported by Gunn (cited in Rice, 1990) who discussed how important the classroom is for influencing and shaping children's perceptions and attitudes. He states that:

Mental images retained from maps are especially powerful because, like television, they are visual and are retained long after the words of the textbook have been forgotten. (Rice, 1990, p. 393). 


\section{New Zealand Studies}

Panckhurst studied New Zealand pre-school children and their interpretations of maps. Her research looked at what young children know about maps and how they acquire their knowledge. Her interest in children's knowledge of maps stemmed from a gap she identified in the knowledge base related to literacy acquisition:

No one seemed to be looking at the systems used in communicating information and ideas through other visual forms, such as charts, diagrams, maps and tables. (Panckhurst, 1989, p. 6)

Panckhurst also looked at map use in the home. This involved finding out what kind of maps were in the home, where they might be kept and the type of map they were. She specifically wanted to find out about the use of maps because "the presence of maps does not mean that they will necessarily be used" (p.125). Her next focus was on who used the maps and for what purpose and finally, the children's involvement with the maps.

Panckhurst interviewed mothers of pre-schoolers and then the pre-schoolers themselves in the pre-school setting. The children completed a "map drawing task and a map recognition task" (p. 136). The map drawing task involved the children drawing a map and explaining it. For map recognition the children had to identify whether a photograph contained a map or not. Similar tasks were adapted for use in my study to ascertain students' understanding of maps. Panckhurst's investigation involved "three levels of inquiry" (p. 124). She first explored questions

about the presence and availability of maps, such as the following: Are there maps in the home? What types of maps? Where are they kept? But the map resources available to the family needed to be broadly defined in order to obtain as comprehensive a picture as possible. (p. 124)

In order to gather such comprehensive information, consideration had to be given to what information was actually required. She stated that:

What was required was not just an inventory of the commercially-produced cartographic maps that resided more or less permanently in the home but a description which took account of maps of the more transient variety - maps displayed on television, in newspapers and magazines, and in the junk mail, 
for example. Other forms of maps created by the children and adults in the home, or brought into the home from outside had to be noted also. Likewise, the maps on public display in community settings needed to be considered as additional resources available to the family. Nor could the play maps and map-like materials used by children in play be omitted. (p. 125)

As the maps in homes may not necessarily be used, her second level of inquiry was "concerned with questions about use" (p. 125). Children's involvement with maps formed the third level of inquiry.

Hardie (2002) explored six-year-old children's language and explanations of the world around them. Her initial thoughts were that "children might be familiar with maps and globes as a result of their social studies work in school" (p. 25) and that most students become familiar with atlases and globes in a school setting. However, in her research involving New Zealand students, Hardie found that "many children said that maps and globes were resources found at home" (p. 25). Social Studies in the New Zealand Curriculum (Ministry of Education, 1997) requires teachers to teach units of work "within a global setting" (p. 20) and Hardie also looked at the nature of increasing globalisation and the effects on student learning. Another consideration that may affect student learning is the increasing number of technologies available today. Students have access to information on the Internet, via email, and through computer games and television. Hardie (2000) describes this increasing globalisation as being "an indirect experience which may influence children" and she continues by describing the ways students can manipulate technology and adds that "it is likely these experiences influence children's perceptions and knowledge of distant places" (Hardie, 2000, p. 8).

\section{Learning and teaching about maps}

Our curriculum requires teachers to teach students about places beyond their local environment. Students all have varying exposure to their environment beyond the four walls of their own homes. It could be said that students from less affluent areas, may have fewer opportunities to travel beyond their local community. This impacts on their understanding of distant places. Brown supports this notion by explaining that starting points for teachers depend:

Not only on the children's previous experience of maps, but also on their personal experiences of the environment. Some children may have had 
experience of air travel, so having the advantage of seeing an aerial view of the landscape; others may have rarely, if ever, travelled beyond the bounds of their home environments. Some may become familiar with maps and atlases through using them at home, or through belonging to organizations such as Cubs or Brownies; the overall prior experiences of maps in any one class of children are therefore likely to be varied. (Brown, 2000, p. 111)

"We each see and construct our own picture of how we think the world is through our own assumptions, experiences and values" (Wiegand, 1992, p. 29). Certainly for the students involved in the study reported in this thesis, the opportunities to travel beyond their local environment varied. Many students in the school where the study was carried out were found to have difficulty understanding that they live in Wellington and that Wellington is a city in New Zealand. Some viewed a holiday in Auckland as visiting another country or as being "far away".

In the United States, "map reading is one of the most frequently taught skills in primary school social studies. Yet tests of social studies skills reveal that primary school pupils are not very good readers of maps" (Muir, 1997, p. 26). One of the reasons Muir gives for this is an "over reliance on symbolic representations. Pupils quickly learn to label a map, but a correct label does not mean that they understand the relationship between a symbolic map and a concrete land area" (p. 26). This is supported by Liben and Yekel (1996) who stated that "children thought that a road depicted by a red line on a map meant that the road itself, was red in the real world" (p. 2781). Welton and Mallan (1996) argue that activities "in which children colour in and correctly label outline maps ... teaches nothing about what maps are or the purposes they serve" (p. 373). They suggest two objectives for activities that help children to create maps by

helping children to visualise their immediate environment from a bird's-eye (or spatial) perspective and helping them to understand that when anything is reduced in size - as maps are in relation to the areas they depict - some things must be omitted. (Welton \& Mallan, 1996, p. 374)

How teachers introduce or use maps in a classroom programme also varies. Acheson and Bednarz (2003) discuss how "few teachers are aware of the growing importance of maps or excited about teaching with and about maps" (p. 1). They define teaching with maps as: 
Using maps in instruction to help students learn key geographic concepts and relationships. Teaching about maps means providing students with the skills and understandings required to read, interpret, and produce maps. (Acheson \& Bednarz, 2003, p. 1)

There is not a lot of research indicating when the teaching of maps should be introduced but "the teacher is the key" (Buggey \& Kracht, 1986, p. 61).

Rice (1990) argues that it is important that children are exposed to a variety of maps. "Different perspectives of the earth can also be gleaned by exposing students to as may different types to maps and views as possible" (Rice, 1990, p. 396). Students need to see, use and talk about maps in as many ways as possible. McGee (1993) supports this view and states that "mapping activities need to be an integrated part of content and set in context. They must have meaning and purpose and not be seen as separate or isolated exercises" (p. 18).

Language plays another role in this. Gerber (cited in Wiegand, 1992) describes maps as "a form of language and children need to master the language in order to maximize their access to the information stored in the map" (p. 127). The complexities of "map language" adds to the language learning of students. The language of maps has been identified by Muir (1997) as "eight distinct map skills appropriate for primary-age children whose spatial development is largely at Piaget's concrete-operational level". These were:

Interpreting symbols, taking perspective, finding location with a coordinate grid, determining direction, calculating distance, viewing elevation, understanding scale, and imagining relief. (Muir, 1997, p. 26)

Students have to have an understanding of how to read the maps and know what the various symbols mean. They need to be able to decode the images they see in a similar way to what they do when they are reading (Welton \& Mallan, 1996).

Another way to view maps and link them to what is taught is by viewing maps as "visual literacy". Georgis, Johnson, Bonomo and Colbert (1999) describe this as "the ability to construct meaning from visual images" (p. 146). Whether reading a book or looking at a map, people create their own mental images of what they are looking at. 
"This ability to see, to comprehend and to think, re-create and communicate graphically is termed visual literacy" (McPherson, 2004, p. 58).

Maxim's (1997) view is that "young students need a firm grounding in world experiences before they are ready to read maps" (p. 206). He goes on to say:

When children experience the world directly, they develop mental structures to which they are able to connect the printed word and thus construct meaning. They also need to participate in many print experiences to develop reading-related behaviours. Learning to read and construct maps is much like the literacy process. Therefore, map skills instructions should begin with experiences that help develop fundamental background knowledge about the world. (Maxim, 1997, p. 207)

\section{Theories of learning about maps}

Several of the authors previously cited refer to how children learn about maps. Piaget's stage theory claims that children need to reach the operational stage before they can understand maps. Vygotsky's social cultural theory leads to an exploration of the role of language and social participation in learning about maps. Activity Theory is related to socio-cultural theory but is less concerned with language than with opportunities to participate with others in the use of maps for real life purposes. Activity Theory claims that we learn by being involved with others in purposeful social activities, such as shopping, or the use of maps on a journey in a car. Children learn from observing and taking part in the use of maps in everyday life. The philosophical roots of both socio cultural theory and Activity Theory can be found in the work of Karl Marx. ${ }^{1}$

The work of NEMP has been referred to already. This project, which commenced in 1993, is designed to assess and report on the achievement of school children in all areas of the curriculum. A small, random sample of students is selected from throughout New Zealand, to be part of this assessment. In 1997 and 2001 information was gathered on information skills and social studies. This included tasks that

1 Engeström (1999), defines Activity Theory as a "Commonly accepted name for a line of the theorizing and research initiated by the founders of the cultural-historical school of Russian psychology, L.S. Vygotsky, A. N. Leont'ev, and A. R. Luria, in the 1920s and 1930s. (p. 1) 
determined students' knowledge of the place they lived in. Results from the 1997 Social Studies report (Flockton \& Crooks, 1998) showed that "about half of year 4 students and 85 percent of year 8 students could place their home location on their own sketch map" (p. 35).

\section{Maps and Literature}

In addition to experiences of the real world as the basis for map understanding children are also exposed to maps through literature. The latest Harry Potter volume Harry Potter and the Chamber of Secrets (Rowling, 1998) and more recently in the movie Harry Potter and the Prisoner of Azkaban, ${ }^{2}$ there is a marauder's map included in the story. This map was brought to life through animation techniques in the movie of the book, Harry Potter and the Chamber of Secrets. ${ }^{3}$ Harry uses this map to guide him around the school buildings and to see where others are. Although this map is a magical map, it shows children ways to locate things or to follow directions, much like a treasure map that they may also be familiar with. The marauder's map also features at the end of the movie with the credits coming up over the image of the map and footprints are also seen moving about the map. Unlike the maps we know, a magic phrase has to be used to get the map to appear and to disappear so that others cannot use it.

Mystery is often associated with maps and how they are used. Some will associate a map with pirates and the rewards of finding hidden treasure. These kinds of maps often appear in television programmes and can be found in children's computer games.

Other well-known children's books that use maps include Winnie-The-Pooh (Milne, 1990). In the front cover of the book is a map showing the location of all the places Christopher Robin visits or knows about. Another picture book that uses a picture to show a map of the world is The Waterhole (Base, 2001). Books that use maps in some way are becoming more common and there is an increasing number of instructional reading texts, which help children to understand how maps work and that explain the features of maps. Examples of these are Making a Map (Haydon, 2002) and The Key to Maps (Chan, 2001).

\footnotetext{
${ }^{2}$ Warner Brothers, 2004. Produced by Alfonso Cuarón.

${ }^{3}$ Warner Brothers, 2002. Produced by Chris Columbus.
} 
One way to link students to maps that are presented in stories is to use real maps and globes so that places they read about can be located quickly. Maxim (1997) states that:

Although the children will not really "read" these maps, they will be practicing the behaviours and acquiring the interest that lead to proficient map reading. Teachers should also use maps while gathering information for their own purposes to demonstrate that map reading is a functional skill, rather than a tedious, meaningless exercise. (Maxim, 1997, p. 208)

Television also plays an important role in exposing students to maps. Children's programmes look at ways maps can be used. Some of these programmes also appear in computer games, which children play within their own home. Games like "Dora the Explorer" or "The Logical Journey of the Zoombinis" are two that are readily available for families to purchase. "Dora the Explorer" also appears on television as a children's programme on the Sky network. Computer technology is such that with keywords, anyone can locate a map or even zoom into one to pinpoint an exact location. A road map or atlas in the traditional book format, may become a tool of the past.

\section{Summary}

Maps are cultural artefacts, a definition that goes beyond a definition which considers maps solely as a skill. This chapter has shown the variety of uses of maps in everyday life including their use for entertainment. There is more than one theoretical explanation relating to how children learn about maps and varying ideas about the way teachers should teach so that children understand maps and can use them. There is a skill in being able to label a map, but children may not necessarily understand the relationship between the labels and the actual land area (Muir, 1997). 


\section{CHAPTER 4}

\section{Methodology}

The research was designed to find out what a small sample of Year 3 and 4 students knew about maps before and after they experienced a 3-week classroom unit on the topic. The unit was not designed as a formal intervention but as a part of the normal teaching programme.

My first step in planning the research was to produce a mind map of what I wanted to find out. The result is shown in Figure 1.

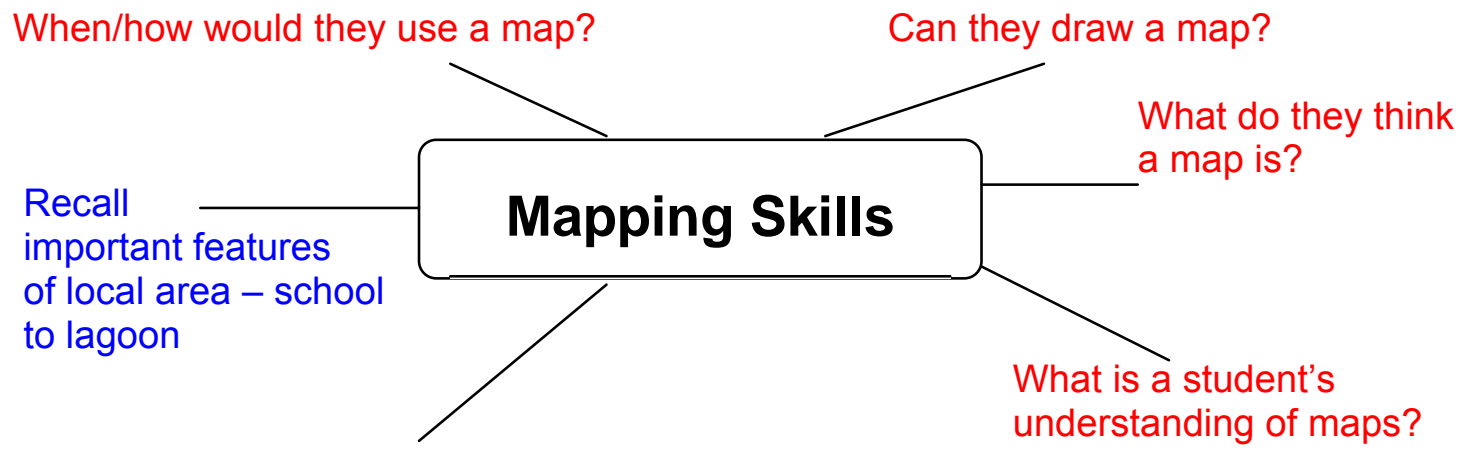

What is the Māori notion of a map? - Traditional knowledge

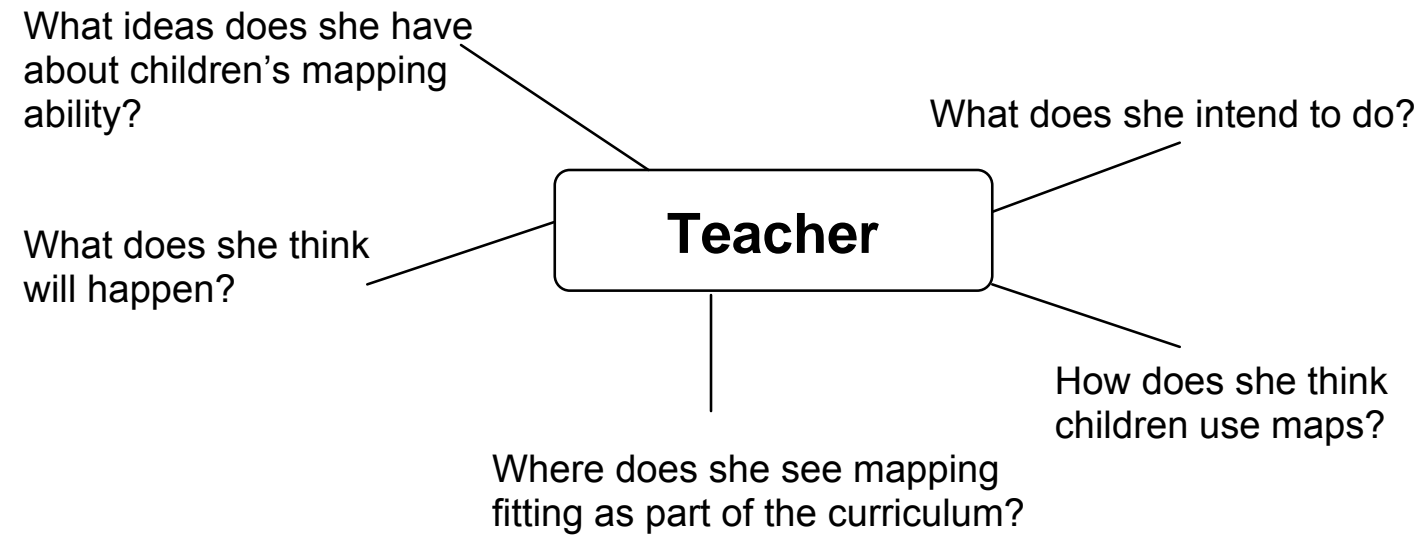

\section{Figure 1: Mind Map}

The mind map showed the possible elements for a study of the map understanding of both students and teachers. The design was far too ambitious and the final focus became students' ideas about maps. However, on the basis of Figure 1 the following questions were developed to guide the research. 
1. What do young school children know about maps and their use?

2. Are young school children familiar with the map of New Zealand?

3. What do they gain from learning about maps in the classroom?

The important questions therefore, were those at the top of the mind map and they are shown in red. The blue questions relate to a possible focus in the classroom during the intervention and led to a decision to interview the teacher after she had delivered the unit on maps.

The design for the research was one in which children were interviewed individually before they took part in the unit on maps taught in their normal classroom. They were interviewed individually, once more, following the unit, at which point the classroom teacher was also interviewed. The research was designed to provide a valid measure of what a small sample of Year 3 and 4 students in one school understood about maps, and to explore from their responses to questions, their experience of maps in family and neighbourhood contexts and real life activities. They were assessed on their ability to identify maps and were asked to reproduce a map of New Zealand. Changes in their understanding of maps and their skill in reproducing a map were analysed following the unit on maps.

The NEMP studies of graphs, tables and maps were used as the basis for ideas for the practical activities used in my study and they helped to shape the general ideas underpinning it.

\section{Procedures}

Although some of the results are presented in the form of numerical tables and graphs, the method of inquiry was basically qualitative, a method described by Denzin \& Lincoln (1994) as:

Mutimethod in focus, involving and interpretive, naturalistic approach to its subject matter. This means the qualitative researchers study things in their natural settings, attempting to make sense of, or interpret, phenomena in terms of the meanings people bring to them. (Denzin and Lincoln, p. 2)

Qualitative research is "concerned with meanings and the way people understand things" (Denscombe, 2000, p.207). Qualitative methods were appropriate to my goal, which was to understand what my sample understood about maps; and to endeavour 
to identify their sources of information in the home, neighbourhood and school.

\section{Sample}

The children chosen for interviewing came from a Year $3 \& 4$ classroom in a Decile 2 school in Porirua. None of the children in the interview group were from the researcher's own class. Eight children were randomly selected by putting all the names of the Māori and then all the Pacific Island children from the Year 3 \& 4 group into a hat. The girls' names were placed into the hat first and two were selected. This was repeated for the boys. This was done in order to represent the population of the school. ${ }^{4}$ Another hat contained smiley faces for the 4 required participants from each group. Sad faces were placed in the hat for the unsuccessful participants. As each name was drawn from one hat, a face was drawn from the other. The eight children selected for interview consisted of 4 girls and 4 boys, 4 were Māori and 4 were from Pacific Nations. Following selection, permission was sought from the families of those selected to take part in the study. All families granted permission.

\section{Interview session}

The first interview session consisted of three parts.

1. The students carried out a selection task in which they were asked to sort maps from tables and graphs by placing them in separate piles (the items used are shown in Chapter 5), The results are reported in Chapter 6. Some of the items for selection were taken from NEMP reports carried out in 1995, 1999 and 2001.

2. The students then answered questions put to them by the researcher. These included questions about family and neighbourhood sources of map knowledge and these questions were informed by the work of Panckhurst (1989). Questions about the location of maps came from teachers' concerns and their knowledge of locations in New Zealand and is reported in Chapter 6 . The schedule of questions is in Appendix $C$ and individual questions are shown with responses in Chapter 6.

3. Finally, the students were asked to draw a map of New Zealand with specific geographical locations. This was similar to a task reported in the NEMP Social Studies Assessment Results 1997 (Flockton \& Crooks, 1998). The results of the "before and after" maps are shown in Chapter 10.

\footnotetext{
${ }^{4}$ There was only one European student in the class.
} 
At the time of this study, the students worked in an open plan classroom and their class was one of three in the block they were in. The students were withdrawn from the classroom for the interview, which took place in a room in the administration block.

The first part of the session consisted of the selection task. In the second part of the session students were asked to answer a series of questions in the form of a face-toface questionnaire. In the third part they drew a map of New Zealand. The sessions took place two weeks prior to the introduction of the unit on mapping. I made observations and anecdotal notes during the course of the session. At the end of the classroom unit on maps, the eight students were withdrawn again for a second interview, which followed the same format, but without the selection task, and to answer a modified form of the first questionnaire in order to assess any changes in their knowledge of maps, their forms and their uses. The questions for the second interview are reported with the results in Chapter 9. Both the first and the second interviews were tape recorded and notes were also taken in case the equipment failed. The questions used for this project were designed to find out about students' understanding of maps. I thought that an interview was a better way of finding out what students knew as opposed to giving them a written task in the classroom. I also wanted to observe what they did as they drew their maps.

The interview was an "artificial situation" but semi structured interviews, where the interviewer still has a clear format, can be flexible enough to allow for the interviewee to develop their ideas (Denscombe, 2000, p. 137). The small sample of students allowed me as the researcher to gain a greater insight into what each individual understood. On a one-to-one basis I could gain an insight into what they were thinking, something that is often difficult to do in a classroom. Allowances were made for "wait time" so that the students had time to consider their answers. Interviewing students is not however, without its difficulties. Students are often reluctant to speak loudly and when recording responses for this study, those unfamiliar with me were less inclined to answer the questions and needed some prompting. Taped interviews with 7- and 8-year-old students do not always go according to plan. Shy students 
may not speak loudly enough to be recorded. Where the students were known to the researcher, it was easier to elicit information. Two of the students did not know me and were quiet and withdrawn.

Most of the questions were asked again in the follow-up session held after the classroom unit on maps. The schedule of questions provided an opportunity for repeating some of the questions for the second interview in order to see whether the ideas that students then expressed owed their origin to the intervention carried out in the classroom.

\section{The Classroom Unit on Maps}

Before the research began, three teachers from the junior syndicate set about planning and implementing a three-week unit on maps. As I was one of the three teachers, I chose to step back and leave the planning of the unit to the other two teachers. I did this in order to avoid any conflict with my research. The syndicate's ${ }^{5}$ focus was to improve student knowledge and to develop their skills in using maps. While there was to be an emphasis on the important geographical features of New Zealand, the students were to look to places in the Pacific where they had links (see plan in Appendix E).

The teacher of the class which included the sample students, took part in the planning and was interviewed after all work with the students has been completed. A record was made of what she reported as her intentions for the classroom unit and to ascertain what she did while implementing it. The written record of her account was checked with the teacher and it can be found in Chapter 8.

\section{Selection of Questions}

The part of the individual interview which involved drawing a map and placing some identified locations on it and sorting maps, graphs and tables, both owe their origin to studies carried out by NEMP. It was also intended to explore whether the home environment was a source of map knowledge and learning and also whether the home gave children access to maps, globes or atlases. The questions were grouped according to maps of different kinds, where each could be located, and whether the students had one or more at home. The questions were also linked so that if the students could not answer the first of the grouped items correctly they had a second chance with another on the same topic.

\footnotetext{
${ }^{5}$ Syndicate - the group of teachers and students working together as a team. In this school there were four syndicates.
} 


\section{The Teacher}

The classroom teacher who was to teach the unit on maps was an experienced teacher. She had been at the school for three years and had agreed to assist with the study and allowed the sample of students to be withdrawn from her class for the two interviews.

\section{Pilot Study}

Before embarking on the study, a pilot project was carried out using Year 2 students from my own class. This enabled me to refine the questions.

\section{Ethics}

The Ethical Guidelines set by NZARE and endorsed by Wellington College of Education (now Victoria University of Wellington College of Education) and distributed in the MAST 500 course taught at the College were followed. My proposal was submitted to the ethics committee and was accepted on the 30 July 2003. (See Appendix $A$ for research proposal).

Prior to embarking on the interviews with the students, written consent was sought from their parents/caregivers and from their classroom teacher. Permission was also sought from the Principal and Board of Trustees. (See Appendix B \& C for the letters). The letters stated that a report would be available. A preliminary report on the study was presented at a conference (Holland, 2004).

The tapes from the students' and the teacher's interviews were transcribed by me. Confidentiality was guarded by storing the transcripts in a folder in a locked cabinet. The audio tapes will be destroyed at the conclusion of the study.

I transcribed the interview with the classroom teacher and it was returned to the teacher for checking.

All students were given pseudonyms in the form of European names. The aim was to avoid identification of Māori and Pacific Nations students because the study was not intended to compare the two groups or to make statements about the performance of either. The sample represented the ethnic profile of the school. 


\section{Limitations of the Study}

The sample was very small and represented the population of a Decile 2 school and so was not representative of all schools. It must therefore be considered as exploratory.

\section{Summary}

This chapter has described the elements of the study, the ways in which the data were collected and the reasons for the choice of items. The ethical procedures and the limitations were outlined. There were many items used in the selection task and they are shown separately in Chapter 5 where the results are presented. 


\section{CHAPTER 5}

\section{Results: Selection Task}

While there is no link to maps in the mathematics curriculum, students are introduced to graphs and tables through links to Level Two of the statistics strand in Mathematics in the New Zealand Curriculum (Ministry of Education, 1992). For example, students are asked to:

- Collect and display category data and whole number data in pictograms, tally charts, and bar charts, as appropriate.

- Talk about features of their own data displays.

- Make sensible statements about the situation represented by a statistical data display drawn by others. ( $p$ 174)

The students were first asked to carry out a selection task in which they were asked to put a collection of maps, graphs and tables into the correct piles. They placed their selections under headings. Once the students had completed placing the examples of maps, graphs and tables in the appropriate categories, they were given a chance to check their results.

The collection of examples of maps, graphs and tables shown below came from examples in an NEMP project in 1999 and a variety of other sources. There were five tables. They are shown in Figure 3. There were six graphs (see Figure 4) and ten maps (see Figure 5).

The examples used in the study were coded according to the letters of the alphabet. The letters used for each category are shown in Figure 2.

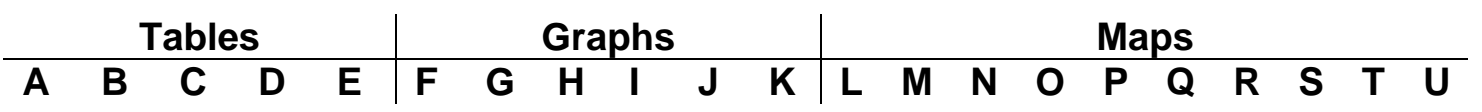

Figure 2: Coding for Selection Items 


\section{$\underline{\text { Tables }}$}

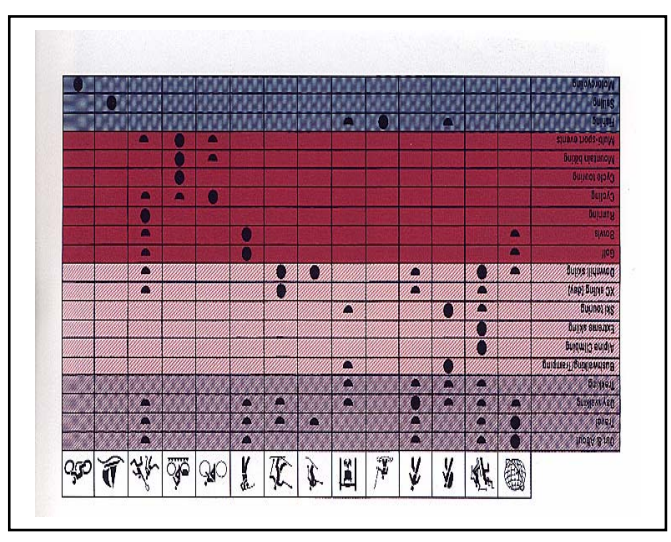

Table A

Suvcy to find the percentage of residents opposed to the develcoment of a skete park in the local donain

\begin{tabular}{|l|c|c|c|c|}
\hline Age grop & $\begin{array}{l}\text { No. males } \\
\text { out of } 50 \\
\text { sunveged in } \\
\text { each group }\end{array}$ & No. ferrales & Total against & \% total \\
\hline Unde 15 & 3 & 7 & 10 & 20 \\
\hline $15-29$ & 8 & 10 & & \\
\hline $30-49$ & 18 & 18 & & \\
\hline 504 & 20 & 24 & & \\
\hline
\end{tabular}

$\operatorname{sen} 20001000000 x$

Table C
Percant of Hours of a Day Spant on Activites

\begin{tabular}{|c|c|c|}
\hline ACTNITY & HOURS & PERCEXT OF OAY \\
\hline Sleep & 6 & 25 \\
\hline Sortiol & 6 & 25 \\
\hline Job & 4 & 17 \\
\hline Entettiment & 4 & 17 \\
\hline Neals & 2 & 8 \\
\hline Horeanok & 2 & 8 \\
\hline
\end{tabular}

Table B

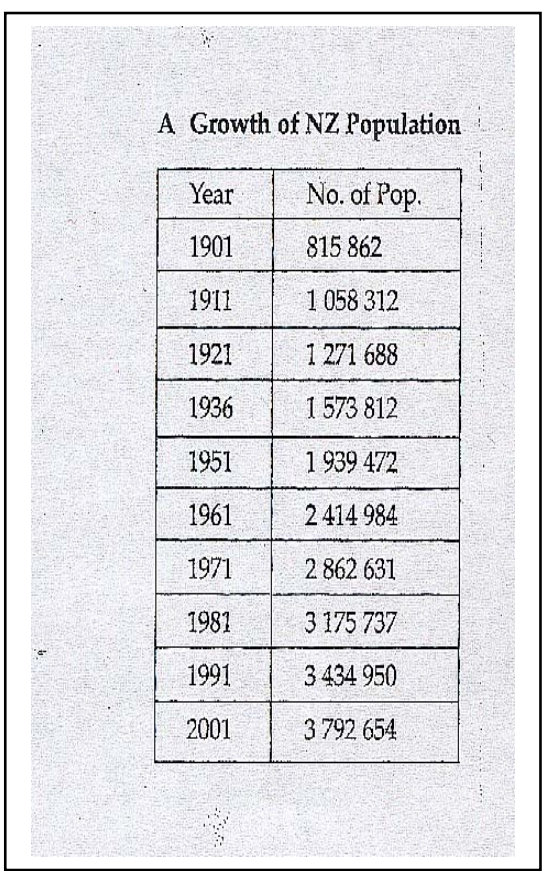

Table D

Table E

Figure 3: Tables 


\section{Graphs}

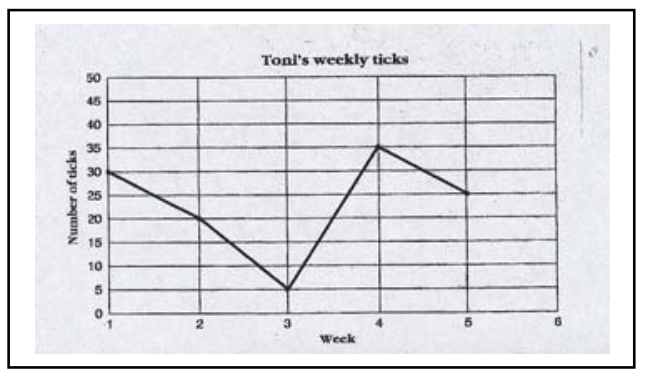

Graph F

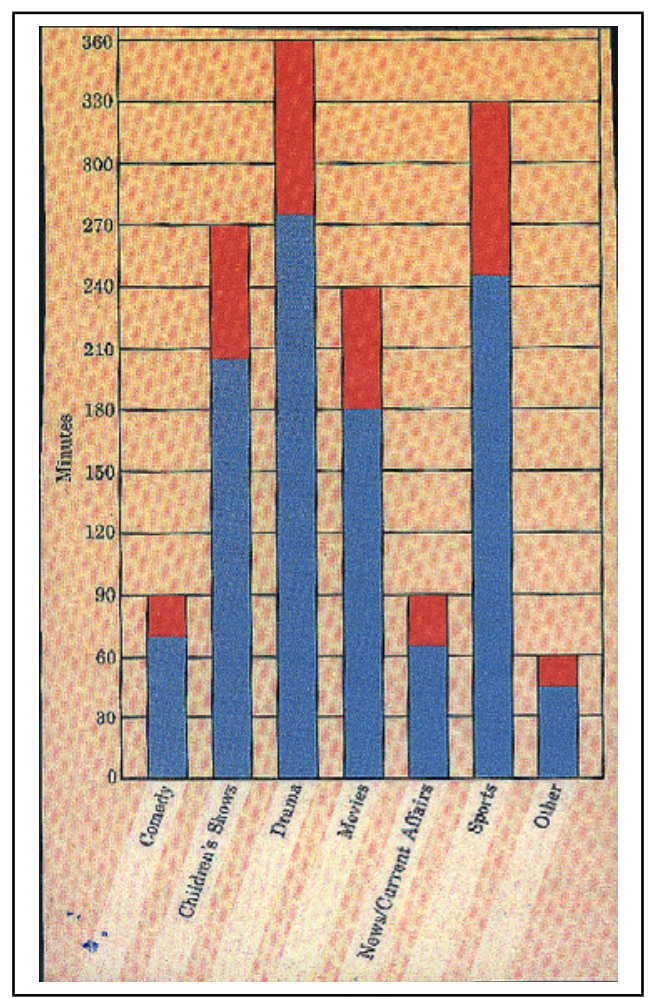

Graph H

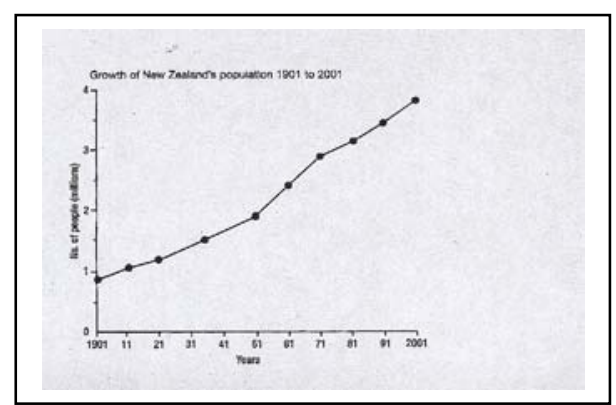

Graph K

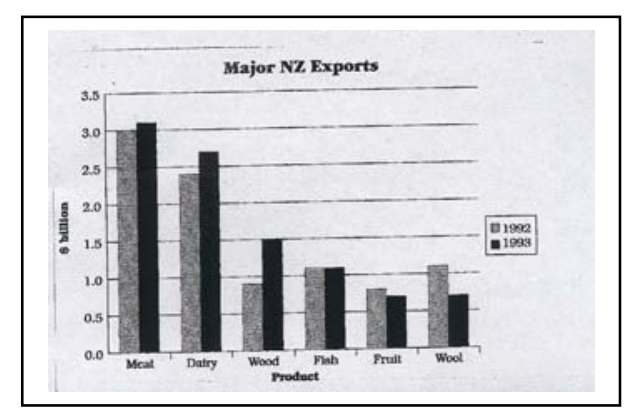

Graph G

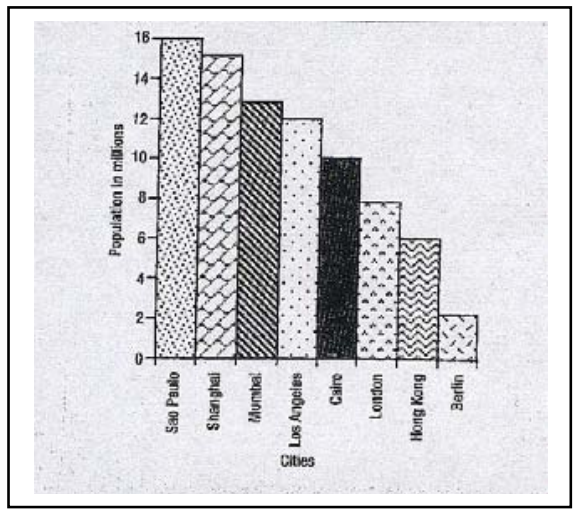

Graph I

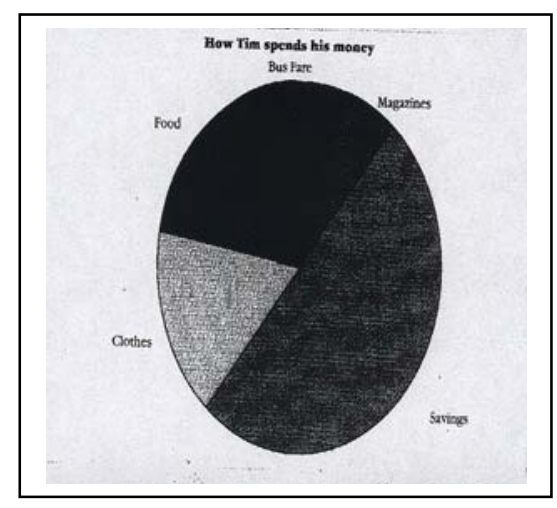

Graph J

Figure 4: Graphs 


\section{Maps}

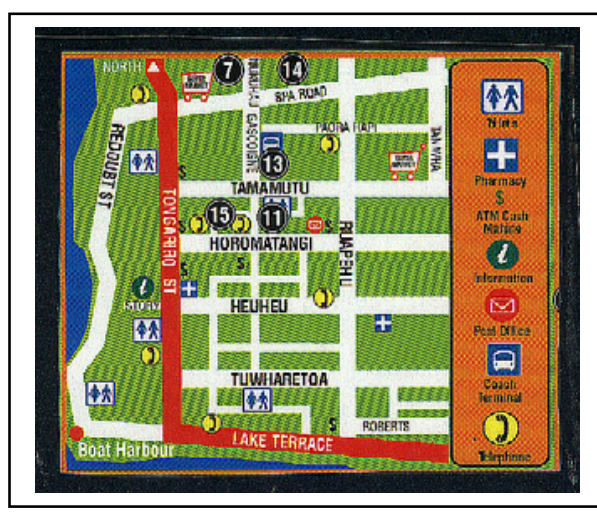

Map L

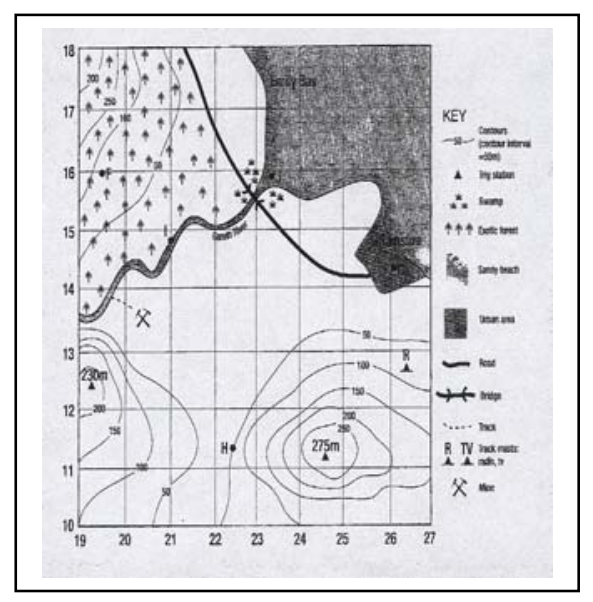

Map N

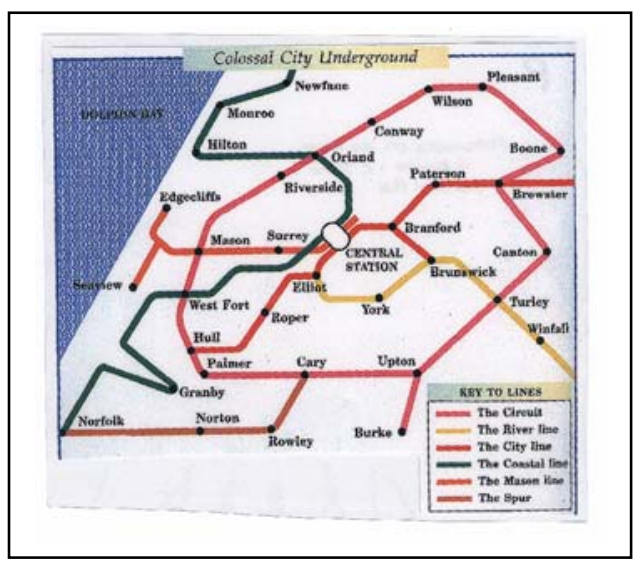

Map P

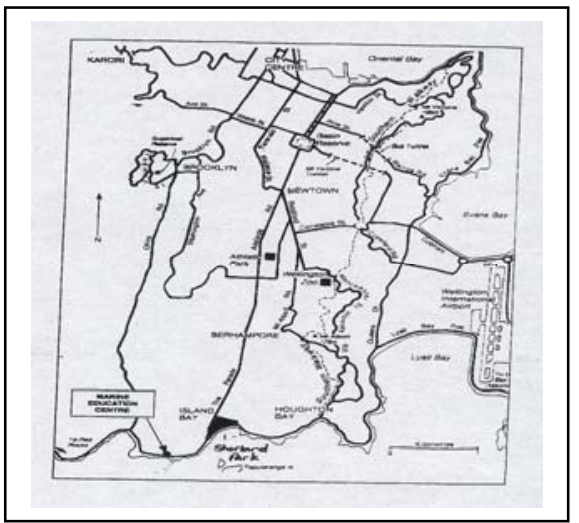

Map M

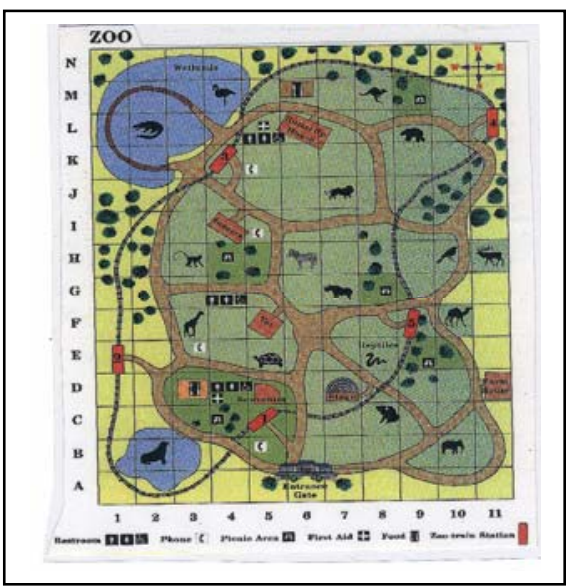

Map O

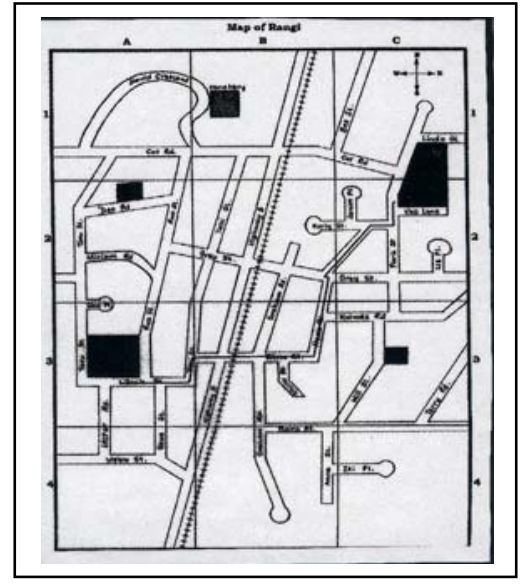

Map Q 


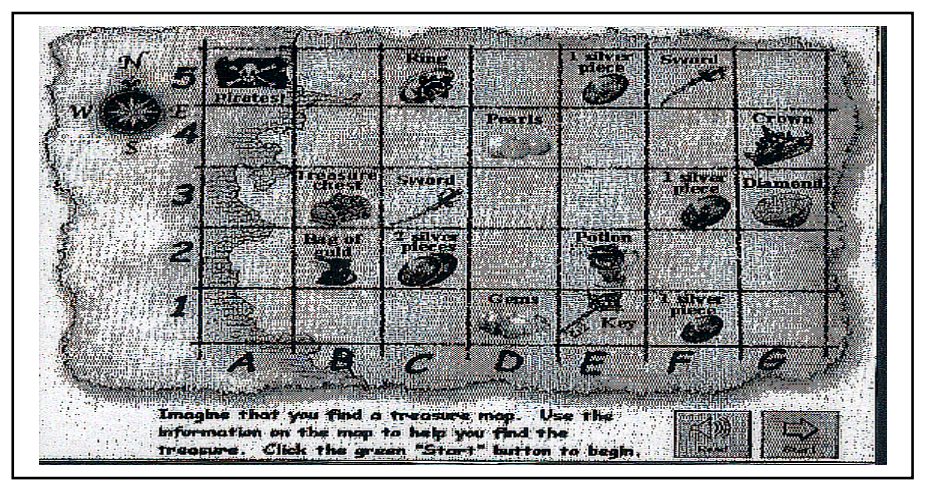

Map R
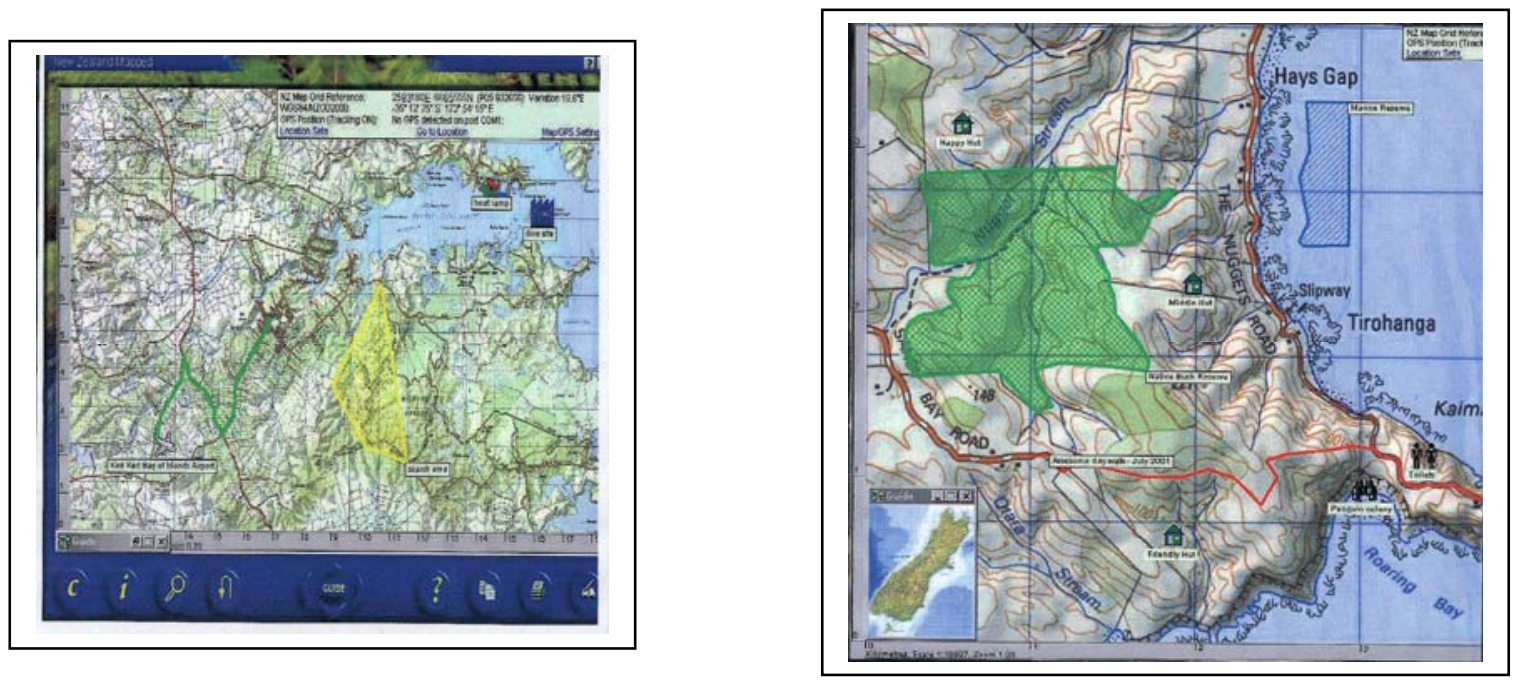

$\operatorname{Map} \mathrm{S}^{6}$

Map $T^{7}$

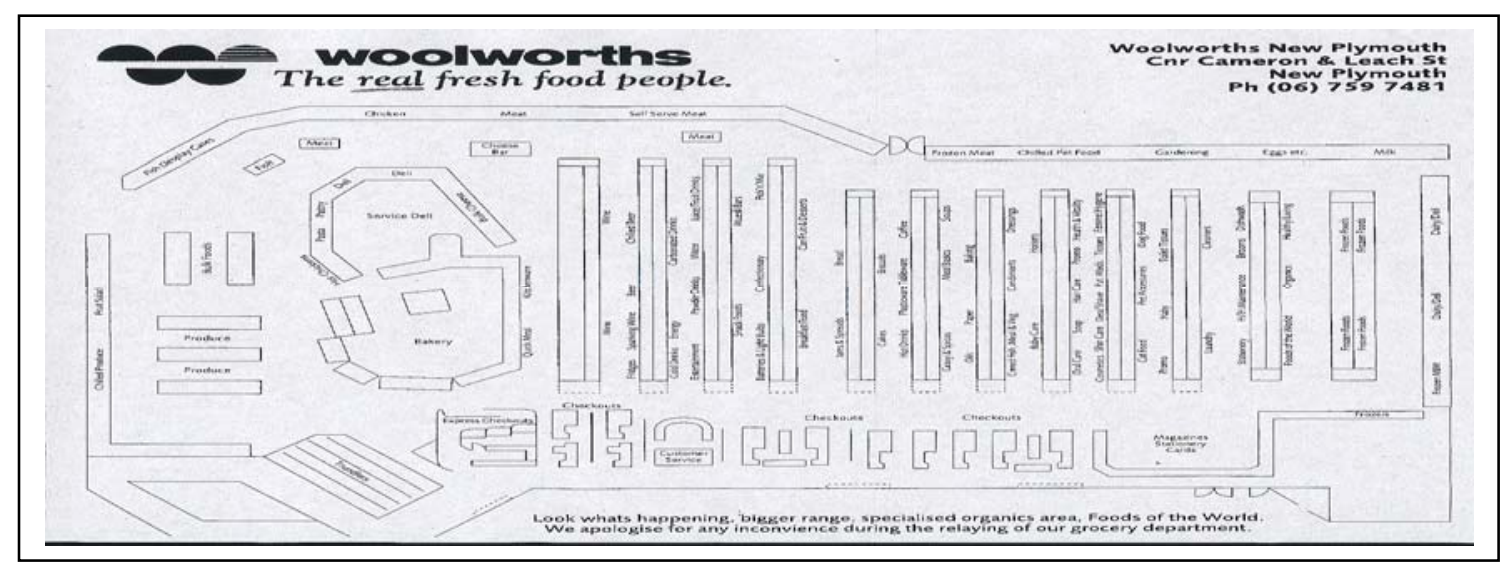

Map U

${ }^{6}$ http://www.polymedia.co.nz/nzmapped/NZM\%20GPS\%20Nugget\%20Pt.jpg (11/5/03)

7 http://www.polymedia.co.nz/nzmapped/BaylsalndsPOI.jpg (11/5/03) 


\section{Figure 5: Maps}

Table 1 shows the number of correct selections for tables, graphs and maps.

Table 1: Correct selections for Tables, Graphs and Maps

\begin{tabular}{lccc}
\hline Students & Tables (N = 5) & Graphs (N = 6) & Maps (N = 10) \\
\hline Rachel & 5 & 4 & 10 \\
Sally & 2 & 6 & 9 \\
Trudy & 2 & 6 & 8 \\
Natalie & 1 & 6 & 9 \\
Karl & 4 & 6 & 8 \\
Liam & 0 & 5 & 8 \\
Chris & 1 & 6 & 8 \\
Roger & 5 & 5 & 8 \\
\hline Total & $\mathbf{2 0}$ & $\mathbf{4 4}$ & $\mathbf{6 8}$ \\
\hline
\end{tabular}

Table 1 shows that there were five tables in the collection. Had each of the eight students selected five correctly the total would have been 40 . In fact there were only $20(50 \%)$ correct selections of tables. There were six graphs in the selection task and a possible 48 correct choices. There were $44(87.5 \%)$ correct selections of graphs. With maps there were ten maps and therefore 80 possible selections. There were $68(85 \%)$ correct selections. These results make it appear that graphs and maps were the easiest to identify while tables appeared to be more difficult for the group. However, there was one item in the map category, which a number of students found difficult. Four of the students placed map R (see Chapter 5) in the graph category. This map was used in the 1999 Social Studies Assessment Tasks by NEMP. The map did in fact look rather like a graph.

Figure 6 shows the data in Table 1 in the form of a graph. It can be seen that Rachel was the most accurate at placing the illustrations in the correct categories, selecting 19 out of the 21 examples accurately. Liam, Chris and Natalie made the fewest correct selections with 13 and 15 correct answers respectively. 


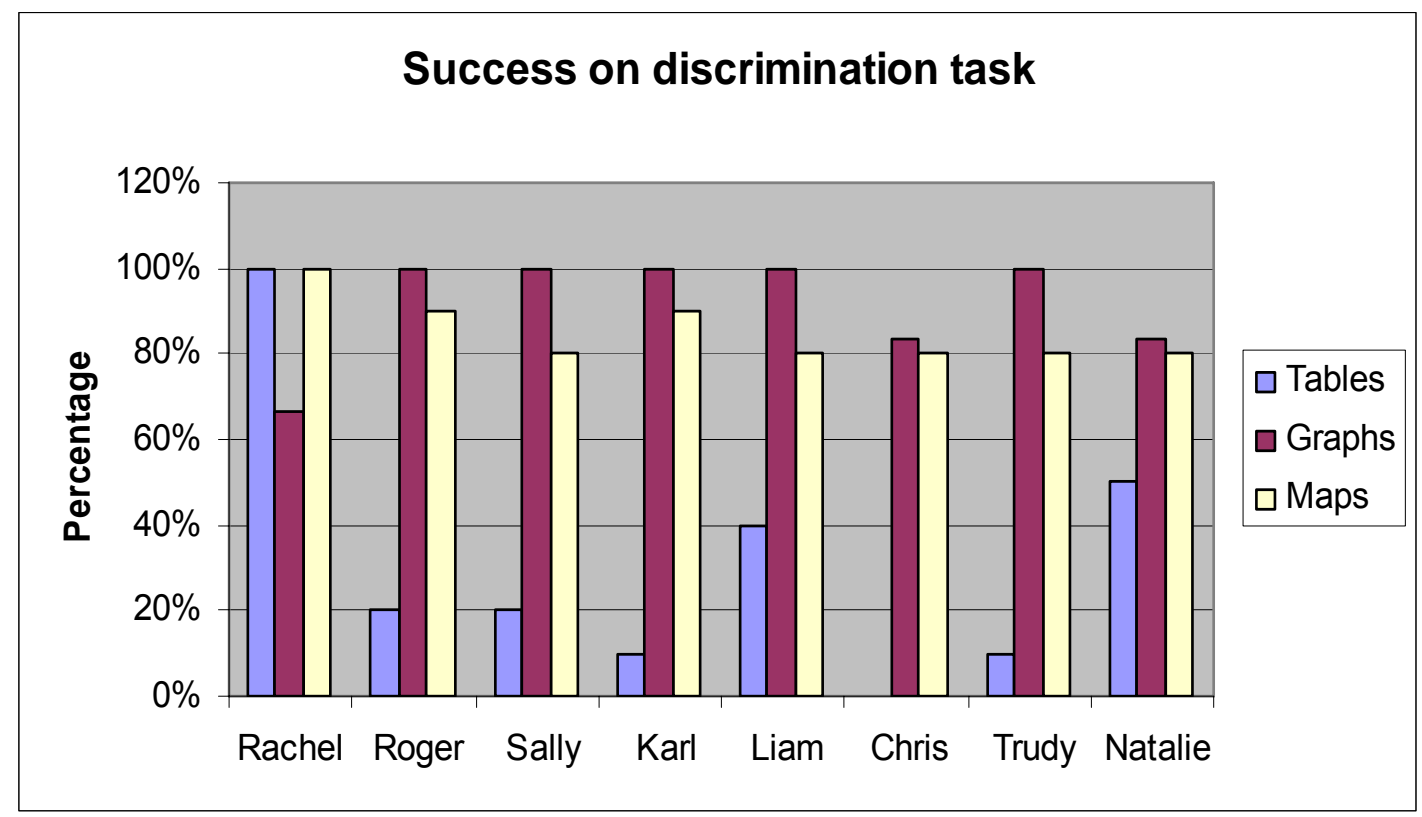

Figure 6: Selections for Tables, Graphs and Maps

Table 2 provides a different interpretation of success on the selection task. It shows the incorrect as well as the correct selections using the alphabetic coding. The incorrect selections are marked in red.

Table 2: Correct and Incorrect Selections for Tables, Graphs and Maps

\begin{tabular}{lccc}
\hline Tables & A B C D E & Correct & Incorrect \\
\hline Rachel & a b c d e f & 5 & 2 \\
Roger & a b c d e k & 5 & 1 \\
Sally & b c f t & 2 & 1 \\
Karl & b c d e n & 4 & 3 \\
Liam & j l r & 0 & 0 \\
Chris & d n & 1 & 1 \\
Trudy & b c & 2 & 0 \\
Natalie & d & 1 & 3 \\
\hline & $\mathbf{5}$ & $\mathbf{2 0}$ & $\mathbf{1 1}$ \\
\hline
\end{tabular}

\begin{tabular}{|c|c|c|c|}
\hline Graphs & $F G H I J K^{*}$ & Correct & Incorrect \\
\hline Rachel & g h i k & 4 & 0 \\
\hline Roger & fghijno & 5 & 2 \\
\hline Sally & $\operatorname{afghijk}$ & 6 & 1 \\
\hline Karl & afghijkr & 6 & 2 \\
\hline Liam & $a b c d e f g h i k$ & 5 & 5 \\
\hline Chris & $a b c e f g h i j k r$ & 6 & 5 \\
\hline Trudy & defghijkpr & 6 & 4 \\
\hline \multirow[t]{2}{*}{ Natalie } & $a b c e f g h i j k r$ & 6 & 5 \\
\hline & 6 & 44 & 24 \\
\hline
\end{tabular}




\begin{tabular}{|c|c|c|c|}
\hline Maps & LMNOPQRSTU* & Correct & Incorrect \\
\hline Rachel & Im nopqrstu & 10 & 0 \\
\hline Roger & a Impqrstu & 8 & 0 \\
\hline Sally & $c \mid m n o p q r s t$ & 9 & 1 \\
\hline Karl & I mopqstu & 8 & 1 \\
\hline Liam & $\mathrm{m} n o p q s t u$ & 8 & 1 \\
\hline Chris & Im nopqstu & 8 & 0 \\
\hline Trudy & a Im noqstu & 8 & 0 \\
\hline \multirow[t]{2}{*}{ Natalie } & Imnopqstu & 9 & 0 \\
\hline & 10 & 68 & 3 \\
\hline Total & 21 & 132 & 38 \\
\hline
\end{tabular}

* The codes are explained in Figure 2 above.

There were 21 possible correct selections (Tables 5; Graphs 6; Maps 10). The 8 students in the sample made 132 or $79 \%$ correct selections out of a possible total of 168. They also made 38 incorrect selections shown in red in Table 2. Since it was possible for the 8 students to have made 336 incorrect choices (Tables 128; Graphs 120; Maps 88 ), 38 or $11 \%$ errors is not a large proportion. However, the most important finding illustrated in Table 2 is that maps were the most reliably selected with only 4 errors from the sample of students. For graphs just over half the selections were incorrect. Table 2 also shows that the students confused graphs with tables on 17 occasions but on only 7 occasions did they confuse them with maps. Mis-selections of maps consisted of putting 3 tables in the map category. The maps were securely identified by the sample of students, while that was not the case for either tables or graphs.

If a student made a large selection, would this increase the number of items correctly selected? A student, like Liam, who made 10 selections for graphs, selected only 5 correct items and when Natalie selected graphs she made 11 selections of which only 6 were correct. Therefore the strategy of "picking as many as possible" appears to work when the correct items are the ones counted. However, if the incorrect items are taken into account, by subtracting the incorrect from the correct selections, then Liam would score none and Natalie 1.

\section{Summary}

The maps, graphs and tables used for the selection task, and their respective coding have been presented in this chapter. The choices that students made for the selection task were reported. It was shown that maps were more easily identified by the students than either graphs or tables. 


\section{CHAPTER 6}

\section{Results: Questionnaire}

The students were questioned after they had made their selections of tables, graphs and maps. The questions asked are shown in italics as are responses from the students. The first question was asked without showing the students a map of any kind.

Have you ever used a map before?

Five out of the eight students said that they had used a map before.

They were then shown a route map and asked what they would use it for. Natalie and Liam responded that the route map could be used to find "where to go". Trudy, Chris and Natalie suggested that you could use it for streets and roads. Only Roger did not know what it would be used for and the others suggested that it was for trains or to go out of New Zealand. Showing the students a route map increased the meaning of the question and 2 students responded who had not answered the initial question.

The students' were then asked the same question but were shown a topographical map. The students did not appear to be as familiar with this type of map. Roger, Liam and Natalie said they did not know. However Liam suggested that it may help with finding your way around New Zealand. Karl and Trudy thought that you might use such a map to find toilets. In the remaining responses, the students showed some understanding of the use of a topographical map. Their suggestions were that the map is used for seeing what is in other countries and seeing where the places are in those countries. This included looking for other cities that you might want to go to.

Route maps and topographical maps are two different kinds of maps but they do not appear to be clearly distinguished in the students' experiences and understanding. 
Three students (Chris, Sally, Natalie) had the idea that you could buy a map or go to the shops to get one. This also included the idea that you could get one from the petrol station. Other responses included "looking under a tree for one - cut it open and dig under it [the tree] or in old places" (Rachel). Two children (Karl \& Trudy) referred to finding one at home and three also suggested that you would find a map in books or at the library or on the Internet. This suggests that this small group of students knows where to look for maps and that they have used them or have seen them used in the family and neighbourhood. The next question asked was specifically about the home as a source of maps.

Do you have any maps at home?

Table 3 summarises the responses.

Table 3: Maps at Home

\begin{tabular}{lccc}
\hline Maps at Home & Yes & No & $\begin{array}{c}\text { Don't } \\
\text { Know }\end{array}$ \\
\hline Rachel & & & 4 \\
Sally & 4 & & \\
$\begin{array}{l}\text { Trudy } \\
\text { Natalie } \\
\text { Karl }\end{array}$ & 4 & & \\
Liam & 4 & 4 & \\
Chris & & & \\
Roger & 4 & 4 & \\
\hline & & & 4 \\
\hline
\end{tabular}

Half the students said that there was a map at home. In order to check on the robustness of these responses the next question was,

Where are they kept?

Students reported that maps would be found

Up on a shelf. (Trudy).

We've got an around the world and one of New Zealand on our bedroom wall. (Sally).

In the cupboard. (Natalie).

Behind the TV. (Liam).

Maybe one in the local directory. (Roger). 
It is possible that the map "behind the TV" was actually a weather map shown on the $\mathrm{TV}$, but this is just the researcher's interpretation. Roger said he did not know whether there was a map in his home but his answer "the local directory" suggests that he had seen a map in a local publication, which would, almost certainly, have been in his home but that he did not interpret this as "having a map at home".

In her study of 4-year-olds' knowledge of maps Panckhurst (1989) found that children could associate maps with journeys by car and so the next questions explored this issue.

Do you have a car and are there any maps in the car?

Table 4 below shows the answers to this question.

Table 4: Maps in the Car

\begin{tabular}{lccc}
\hline Maps in the Car & Yes & No & $\begin{array}{c}\text { Don't } \\
\text { Know }\end{array}$ \\
\hline Rachel & & 4 & \\
Sally & & 4 & \\
Trudy & 4 & & \\
Natalie & 4 & & \\
Karl & & 4 & \\
Liam * & & 4 & \\
Chris & & 4 & \\
Roger & & & 4 \\
\hline & $\mathbf{2}$ & $\mathbf{5}$ & $\mathbf{1}$
\end{tabular}

${ }^{*}$ This family does not have a car.

What are they used for?

The students' comments included:

Going to streets, to Auntie's and Mum's friend's house. (Trudy).

They would show if we're going out somewhere to show where we're going. (Sally).

My mum leaves it in there so when we go on a trip we know where to go. (Natalie).

The students were familiar with what maps could be used for. They knew that you need a map to find out where you are going and having one in the car is useful as it provides a reference not only for where you are going, but also how far you may have to travel. Karl demonstrated understanding about maps and the distance you need to travel as he suggested that a map could be used for "my brother - he goes to New Plymouth. Sometimes my Dad needs a map for that". The question was a general 
one but the students reported activities involving maps in which they have been involved "when we go on a trip", or knowledge which came from observations of school activities.

The next question explored the students' knowledge of an atlas, an artefact which contains maps.

Can you tell me what an atlas is?

Karl, Liam and Trudy did not know what an atlas was. Karl's response was, "I haven't even heard of it". Of the remaining five responses, four students knew that an atlas was a book that depicted maps in some way. This included whether the atlas showed "maps of special stuff and streets" (Sally), recalling a use for finding locations. The remaining response was that an atlas was a "sort of ball that you turn around to see different parts of the world" (Roger). Roger had demonstrated a knowledge of maps but showed confusion between an atlas and a globe.

The next questions asked whether the students had an atlas and whether they knew if they had one at home or at school.

Do you have an atlas?

Table 5 summarises the responses.

Table 5: Atlas at Home or School

\begin{tabular}{|l|c|c|c|}
\cline { 2 - 4 } \multicolumn{1}{c|}{} & \multicolumn{3}{c|}{ Atlas } \\
\cline { 2 - 4 } \multicolumn{1}{c|}{} & Yes & No & $\begin{array}{c}\text { Don't } \\
\text { Know }\end{array}$ \\
\hline Rachel & & & 4 \\
\hline Sally & & 4 & \\
\hline Trudy & & 4 & \\
\hline Natalie & 4 & & \\
\hline Karl & & 4 & \\
\hline Liam & & & 4 \\
\hline Chris & & 4 & \\
\hline Roger & & $4^{*}$ & \\
\hline \multicolumn{2}{l|}{} & $\mathbf{5}$ & $\mathbf{2}$ \\
\hline
\end{tabular}

\begin{tabular}{|c|c|c|}
\hline \multicolumn{3}{|c|}{ At Home } \\
\hline Yes & No & $\begin{array}{c}\text { Don't } \\
\text { Know }\end{array}$ \\
\hline & & 4 \\
\hline & & 4 \\
\hline & 4 & \\
\hline 4 & & \\
\hline & 4 & \\
\hline & & 4 \\
\hline & 4 & \\
\hline & & 4 \\
\hline $\mathbf{1}$ & $\mathbf{3}$ & $\mathbf{5}$ \\
\hline
\end{tabular}

\begin{tabular}{|c|c|c|}
\hline \multicolumn{3}{|c|}{ At School } \\
\hline Yes & No & $\begin{array}{c}\text { Don't } \\
\text { Know }\end{array}$ \\
\hline & & 4 \\
\hline 4 & & \\
\hline 4 & & \\
\hline 4 & & \\
\hline & 4 & \\
\hline & & 4 \\
\hline 4 & & \\
\hline & & 4 \\
\hline $\mathbf{4}$ & $\mathbf{1}$ & $\mathbf{3}$ \\
\hline
\end{tabular}

* used to

Of the eight students, only Natalie reported having an atlas at home. Two did not know. Roger said that they used to have an atlas at home. The students were more aware of atlases at school and where they were located within the school. Chris described exactly where to find an atlas in the classroom, "in the middle of Rimu Block". 
Both Rachel and Liam answered that they did not know where the atlases were either at home or at school. Rachel, however, had given a correct response to knowing what an atlas was in an earlier question illustrating one of the problems of establishing knowledge from young school children who may not have known the interviewer well or that the question was not important to them.

The next question involved prompting the students to think about where an atlas might be found.

Where would you find one? Are there any in the classroom? Where are they? The first of these questions was put to each student with the remaining two as prompts to find out what other knowledge the students had. Four students knew that you would find an atlas at school. They also knew that they would be in classrooms. Natalie and Rachel were able to give the exact location for the atlases in the classroom. Rachel however, thought that you might also find an atlas in the bushes or at other people's houses. The other four students did not know, or were not sure, where they would find them. Trudy suggested that they might be on a shelf at home or in the wardrobe but said there were none at school.

It is possible that the school and the shop referred to in an earlier question are associated in children's minds with where things might be found and a shelf is a familiar place to store things. The students often appeared to have picked up clues from earlier questions.

\section{What is an atlas used for?}

Trudy did not know what an atlas was in answer to question 6. Her answer to this present question was that she did not know what an atlas was used for, but it could be for "telling people something or telling what things are". One of the difficulties in interviewing young children is knowing whether they understand the question. In some cases, they demonstrated knowledge relating to maps but did not seem to know how to match that knowledge to the actual question asked.

Do you use a globe?

Nearly all the students answered "no" to this question. Roger said "sometimes" and when asked what a globe might be used for, responded with "anything". Rachel's response was, "Is it a thing that shines, a torch kind of?" probably associating a globe 
with an electric light. Chris had the most interesting response. "I know what it is but I haven't used one. A globe is a shape of the world that you turn around and see all the countries".

What is a map used for?

These were the responses for this question.

To find your way to different places/so you know what street to go on so you don't get lost/finding your way around. (Roger, Natalie, Karl).

For when people get lost, they could look at a map. (Rachel).

When you are stuck. (Chris).

Going on an aeroplane and asking them where you want to

go. (Rachel).

Helping you around the island and around towns. (Liam).

To take you to other places around cities. (Sally).

In a new country to find your way around. (Chris).

Going to your friend's house, ringing up and asking them where to

go. (Trudy).

To show where places are/where to go. (Sally).

The first three responses relate to being lost. The next four are linked with travel and the remainder are general responses relating to going somewhere. All the responses are associated with needing to find your way around an unfamiliar location and are the uses that children had reported earlier as encountered in everyday life.

The next question sought more contextualised answers requiring a practical rather than an abstract response.

If your mother wanted to go somewhere and she didn't know exactly where to go, what should she do?

All the students, no doubt stimulated by the earlier questions, responded that she should try and get a map or ask someone where to go. Two had interesting responses.

Go to the centre and buy a map. Ask for directions. Use a cell phone; got a map on a cell phone. (Chris).

She could go somewhere else or say "Rachel, where is the place of Australia?" and I'd say "It's overseas." That would be funny. (Rachel). 
At the time of the interviews, Vodafone had just launched a new range of cell phones. In the advertising campaign, they showed a group of people looking at a map on the phone. Chris's dad had just got one of these phones. Chris had obviously been impressed by a map on a cell phone.

The next questions endeavoured to find out what the students' knew about using maps to locate particular places.

How would you find your street in your town?

By looking at the signs. (Rachel).

Asking people. (Karl, Rachel).

Use a map. (Roger, Liam, Chris).

Ask people and looking at a map. (Trudy).

Look on a map of New Zealand. Look for [the name of the city], then go down and see what streets near you and see if you can find [the place where you live]. (Sally)

By remembering the street. (Natalie)

How would you find a city in another country?

The students made the following responses

Find your own way there. Look on these things and ask people. We might see a house and it may be empty and we could move in. (Rachel).

Use a map. (Chris).

Asking your mum. (Trudy).

Look at a map about the world and find a city in the map. (Sally).

On those big square maps that says what country it is. (Natalie).

Don't Know. (Roger, Liam, Karl).

What can be noted is that the concept of locating yourself or finding your way around produces more concrete responses than ones about atlases with which the students were less familiar.

The next question looks at how the students would use a map.

How would you find out how to get to someone's place?

By asking what directions from them. Like I didn't know where my dad was his house lives down the road from ours. (Rachel). 
Chris was very practical.

Ring them up. Ask friends. (Chris).

So were Trudy and Natalie.

Ringing them up and looking at a map. (Trudy, Natalie).

But Liam would;

Use a map. (Liam).

Sally knew exactly what to do.

Need to know where they live first. Need to know if they live in [the name of the suburb] then look on a map of [the name of the suburb] and see where the street is. (Sally).

Asking people for directions. (Karl).

Don't know. (Roger).

The next question is typical of the kind of questions a teacher might ask.

If I told you I wanted to see some maps, and I wanted you to find one for me, could you find some for me?

All but two students knew how to find a map for me. Roger did not know if he knew how to find a map and Karl, who replied "no", did know where he could go to locate one.

This question was followed up with:

Where would you go?

In my classroom, there's one on the wall by the library. (Karl).

Go by the dictionaries. (Natalie).

I might go to the non-fiction books. Find a book that has maps in it. I might go in the classroom and they might have map. By the office, it's got a map around the school. (Sally).

In town and around beaches. (Liam).

On shelves, at school. Ask someone if you could borrow one. Ask Mum and Dad. (Trudy).

At school. Don't know. (Roger).

Library or in the middle of [the classroom block]. (Chris).

I'd go hunting around the house and outside, hunting in the bushes and hunting everywhere. (Rachel). 
Rachel's answer revolves around hunting for an atlas and probably this is true also of Liam's answer. This question showed the value of the library for information. The students are familiar with the layout of the school library as they have weekly visits. They also know where the local library is. Some make regular visits there with their families and have been there as part of a school trip. These students were being interviewed by a teacher in a school setting and this probably directed their attention to a school perspective.

The students were then asked:

\section{What does reading a map mean?}

The students found this question difficult. Four did not produce an answer. The other four all referred to looking at the map and attempting to find the street or the location you are seeking. They associated the question with a route map. Two were more precise with their response. Chris said that you could "just read all the countries", suggesting that he was thinking of a map of the world. Natalie suggested that reading a map was "like you read a map and you look at it and you see what street or the place you're looking for - the city". Both these ideas may have come from the word "reading". They have transferred this understanding to looking at a map and realising that you can look at it or "read it" to find the information you need. Rachel had said that reading map meant, "you could get information".

Having asked what the students knew about reading a map, they were then asked the following question:

\section{Can you read a map? How do you do this?}

Seven out of the eight believed that they could read a map. Roger thought he could. In the previous question the students had difficulty explaining what reading a map meant, but were able to state that they could, which again illustrates the students' ability to answer an abstract question, while not necessarily understanding it. Rachel related her ability to read a map by saying that she could read a map and that "you look on the map and you could spell, you could read it". Two others linked some of the skills taught in reading by suggesting that you "sometimes look at the contents page on it" (Roger) or "you look for a country in look it up in a glossary" (Chris). They knew that reading a map involved using a contents page or a glossary, being able to spell and sound out letters to find the place you want and to look for streets. Sally suggested that you "have to look/find lines of places - just like any place of New 
Zealand and it will have a line to show where it is". They associated reading a map with reading text.

They were then asked:

Do you ever draw maps? What do you do this for?

Only two of the eight students said that they drew maps. These two students, Trudy and Rachel, drew maps for fun and usually with friends.

\section{Summary}

The students had trouble distinguishing tables from graphs but had little trouble distinguishing them from maps. The answers to the questions about maps show that the students were familiar with the uses of route maps, which they seemed to have observed in use and had been part of activities in which such maps were involved. Maps appeared to be present in most of their homes. Tables and graphs are not so likely to be found in the home and though they may appear on notices in neighbourhood settings, the children are unlikely to be using them in these places. The difference in use could well explain the findings from the selection task. 


\section{CHAPTER 7}

\section{Results: Drawing a map of New Zealand}

The unaided sketch map of New Zealand was based on a similar task used on students at Year 4 and Year 8 by NEMP (Crooks \& Flockton, 1998).

When the students had answered the questions they were asked to draw a map of New Zealand and to place the following locations on it:

Wellington

Auckland

Christchurch

Dunedin

Lake Taupo

Mount Taranaki

Stewart Island

The students were then given the opportunity to tell the interviewer about their map and to explain why they had placed the locations where they were on their maps. Their responses to this are reported at the end of this chapter.

\section{First Map Drawings}
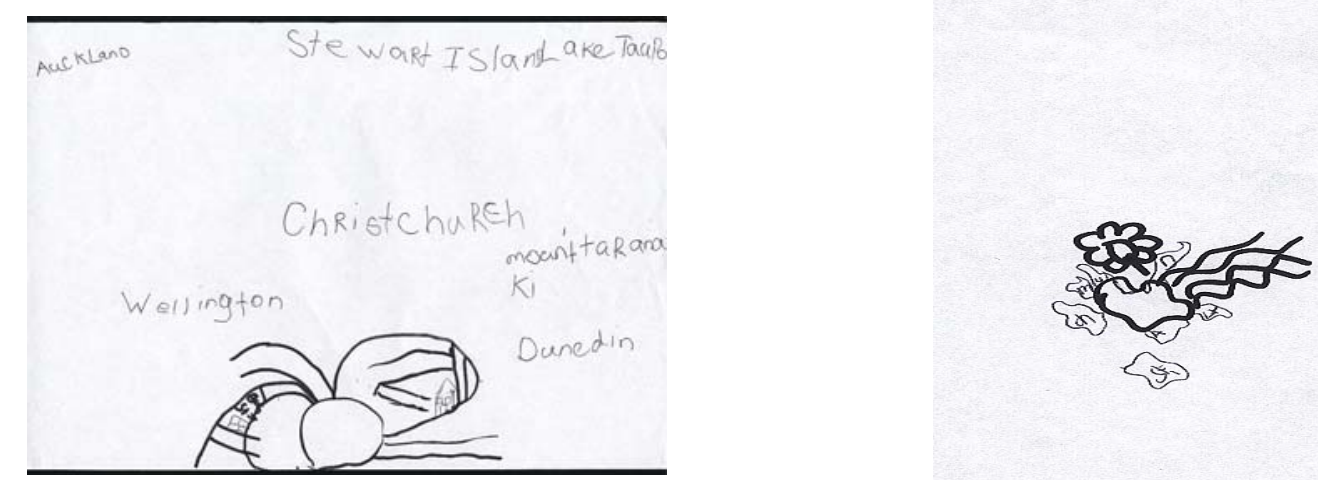

Rachel 


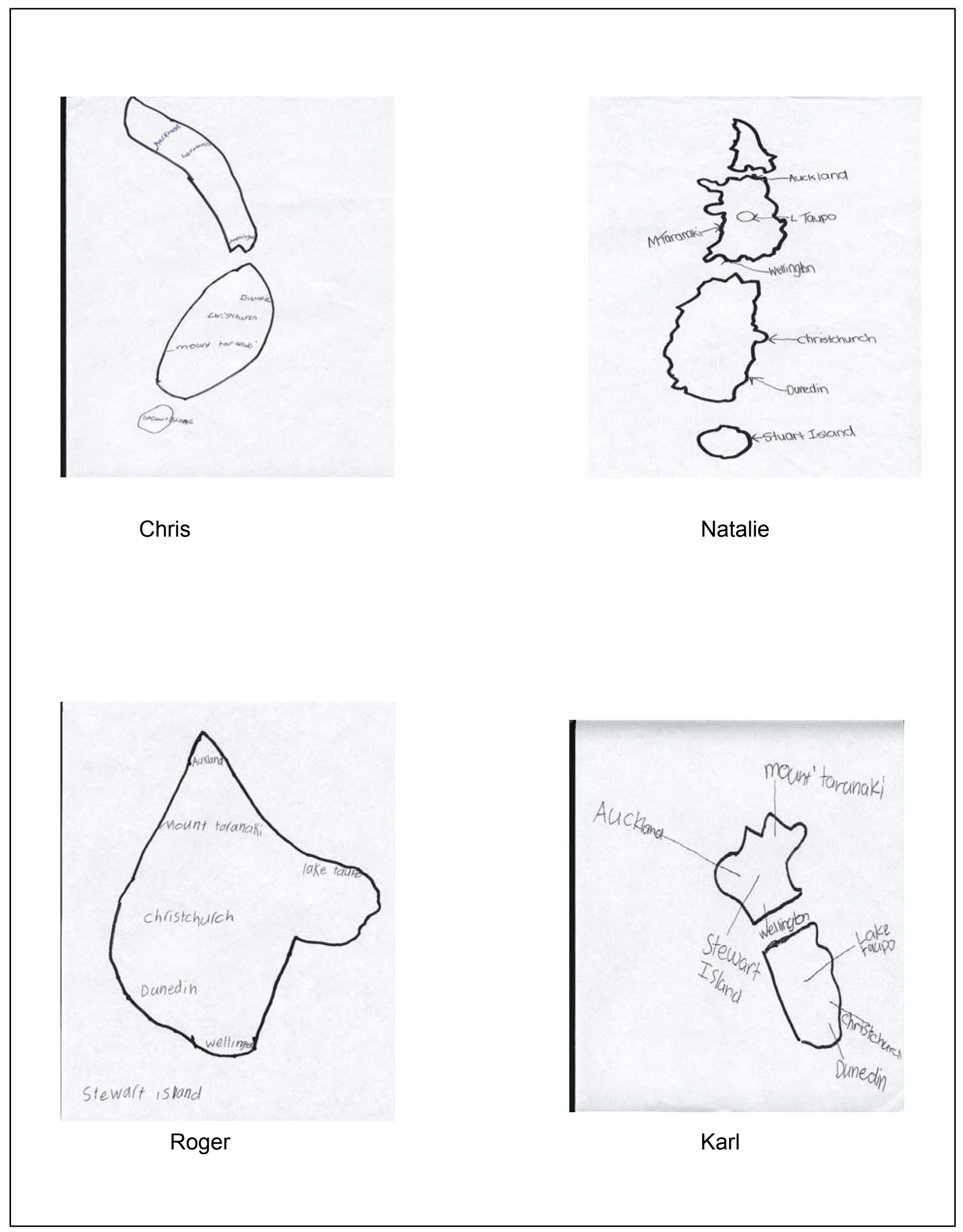




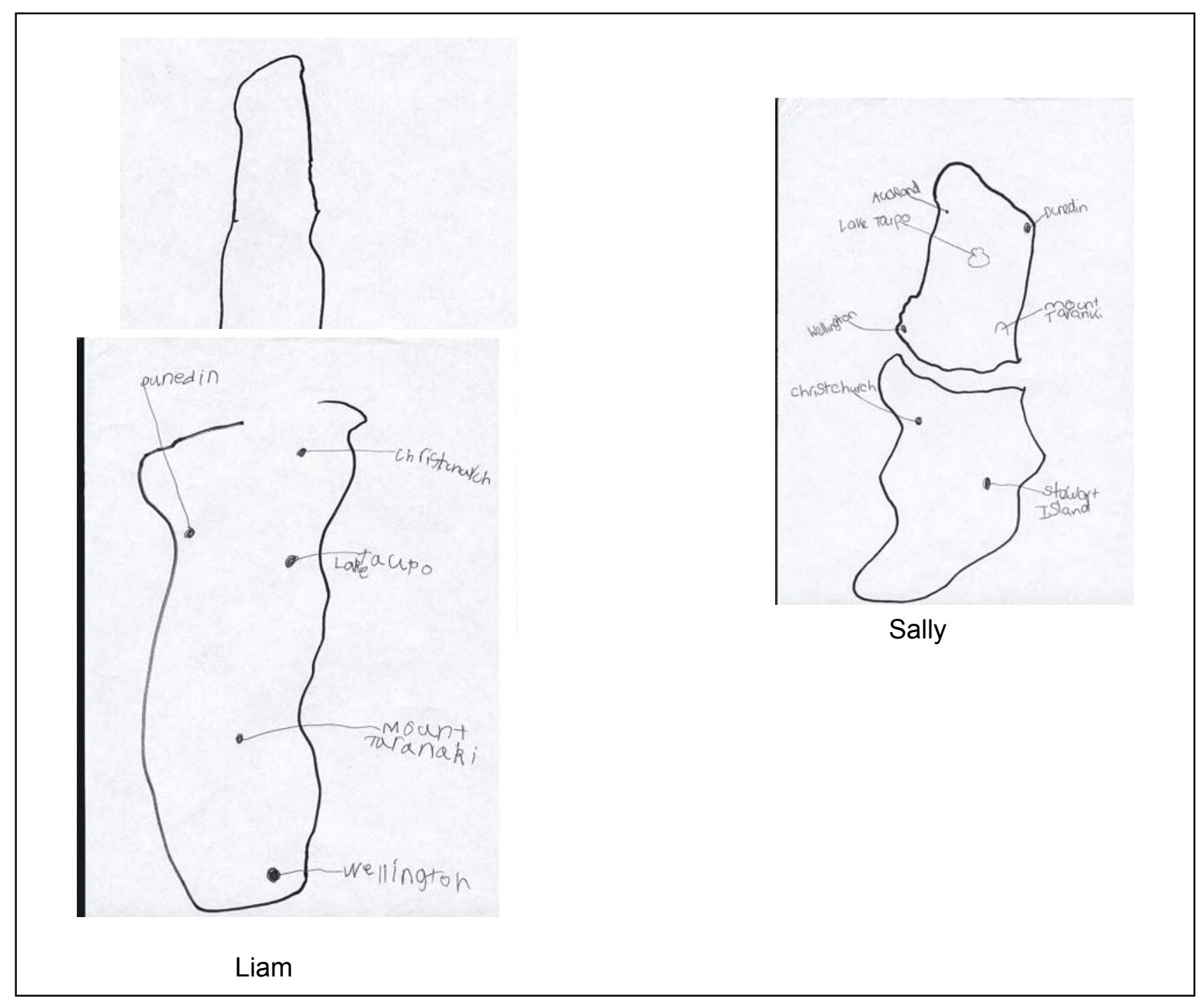

Figure 7: First Map Drawings

\section{Map of New Zealand:}

Assessment of this task looked at how well the students managed to get the general shape of the islands that make up New Zealand and how they identified them. Table 6 shows the student's success at drawing New Zealand as measured by scales relating to the number of islands, the proportions of the two main islands and the shape or relative position of the islands.

\begin{tabular}{ll|ll|ll}
\hline \multicolumn{2}{c|}{ Islands } & \multicolumn{2}{c|}{ Proportions } & \multicolumn{2}{c}{$\begin{array}{c}\text { Shape and relative } \\
\text { positions of the islands: }\end{array}$} \\
\hline 3 main islands & $\mathbf{1}$ & About right & $\mathbf{2}$ & Approximately correct & $\mathbf{3}$ \\
2 main islands & $\mathbf{2}$ & North Island too large & $\mathbf{1}$ & Good attempt & $\mathbf{1}$ \\
other & $\mathbf{5}$ & South Island too large & $\mathbf{0}$ & Little resemblance & $\mathbf{4}$ \\
& & Not applicable & $\mathbf{5}$ & & \\
\hline
\end{tabular}

Table 6: Initial Shape and Proportion of the Islands 
Placement of Locations:

Table 7 shows the results from marking 7 locations on the sketch map.

Table 7: Initial Placement of Locations.

\begin{tabular}{lccc}
\hline Locations & $\begin{array}{c}\text { General area in } \\
\text { correct island }\end{array}$ & $\begin{array}{c}\text { Correct } \\
\text { island, but } \\
\text { misplaced* }\end{array}$ & Incorrect \\
\hline Auckland & 6 & & 2 \\
Wellington & 5 & 2 & 3 \\
Christchurch & 3 & 2 & 3 \\
Dunedin & 2 & 3 & 4 \\
Mount Taranaki & 1 & & 4 \\
Stewart Island & 3 & 1 & 5 \\
Lake Taupo & 3 & $\mathbf{8}$ & 4 \\
\hline Total & $\mathbf{2 3}$ & & $\mathbf{2 5}$ \\
\hline
\end{tabular}

* 'Misplaced' meaning not in its regular or correct location.

To complete these drawings, the students had to rely on their memory of what New Zealand looked like and it was assumed that they had seen a map of New Zealand in order to reproduce it. Each of the students made some attempt to represent New Zealand as they thought it looked and Natalie managed to get the general shape mostly correct.

Sally and Natalie placed Lake Taupo in the centre of the North Island. Natalie and Chris drew Stewart Island. Roger also placed Stewart Island on his map. He wrote the words but did not draw an Island. Liam drew what looks like the North Island as his map of all of New Zealand. Rachel drew what is more like a road map, placing the locations outside of the map she had drawn. Her map shows her house and the bus stop, showing that she perhaps knew that you had to travel to get to the other locations.

\section{Student Responses}

The students were asked to explain their drawing and to give an explanation as to why they placed the locations where they were.

"Tell me about your map" drew the following responses.

I don't really know what New Zealand looks like. (Roger)

In reference to Stewart Island. Does it have to be on the map? Can it be around the outside? (Roger) 
It has water and flowers. (Trudy)

Can I draw streets? (Rachel)

Stewart Island is part of New Zealand. (Natalie)

Their explanations about why they made their choices of placement include:

I saw Auckland and Stewart Island on the news. (Roger)

I don't know why the places are there. (Trudy)

I know how to draw New Zealand because it's where we live. Stewart Island is not part of New Zealand. (Liam)

I remembered some places like Auckland. I know that Lake Taupo is in the centre. I've never seen Christchurch and I don't remember Mount Taranaki. (Karl)

Wellington goes down by New Zealand. There's a bus stop and a doubledecker bus. A path to go to the shops or to go to somebodies house. (Rachel)

I know that Wellington is near the bottom and Auckland is at the top. Christchurch was down here (pointed in the direction of the South Island) and Lake Taupo is at the bottom. (Sally)

Well Stewart Island is part of New Zealand. (pointed to Christchurch) My cousins live there. I went there last year at Christmas. (Natalie)

Chris had no explanation at all.

From this we can see that there is a large variance in their understanding about maps. It is important to look at Rachel's map to understand why she made reference to the bus stop. The students were also divided over whether Stewart Island was part of New Zealand or not. They also placed Wellington at the bottom of an island.

\section{Summary}

The students' sketch maps produced before the intervention showed varying degrees of shape and size. They had difficulty placing locations on their map, but did manage to place Auckland and Wellington correctly. Their comments about their drawings reflect the stages they are at in understanding about locations in New Zealand. They could also reflect upon the experiences they have of travelling in New Zealand. 


\section{CHAPTER 8}

\section{Classroom Intervention}

Between the first and second interviews an intervention occurred in the classroom. During the intervention Pam, the classroom teacher, carried out a series of lessons each of which took between 30 minutes and an hour. Some of these lessons were carried out in the afternoon and were linked to part of the Social Studies curriculum. Others were integrated into reading and mathematics programmes. Sometimes she worked with small groups and at other times with the whole class.

All eight students came from the same room, so Pam was able to deliver the same programme to them all. Prior to the introduction of the unit, the three teachers in the syndicate met to plan the unit. An outline plan (appendix E) was drawn up.

In the time leading up to the classroom unit, Pam collected examples of maps, graphs and tables to put on display. Some were laminated so the children could use them and trace various routes with pens. In this collection was a variety of maps from the Wellington region, but also maps of places throughout New Zealand. Figure 8 shows some of the maps Pam collected.
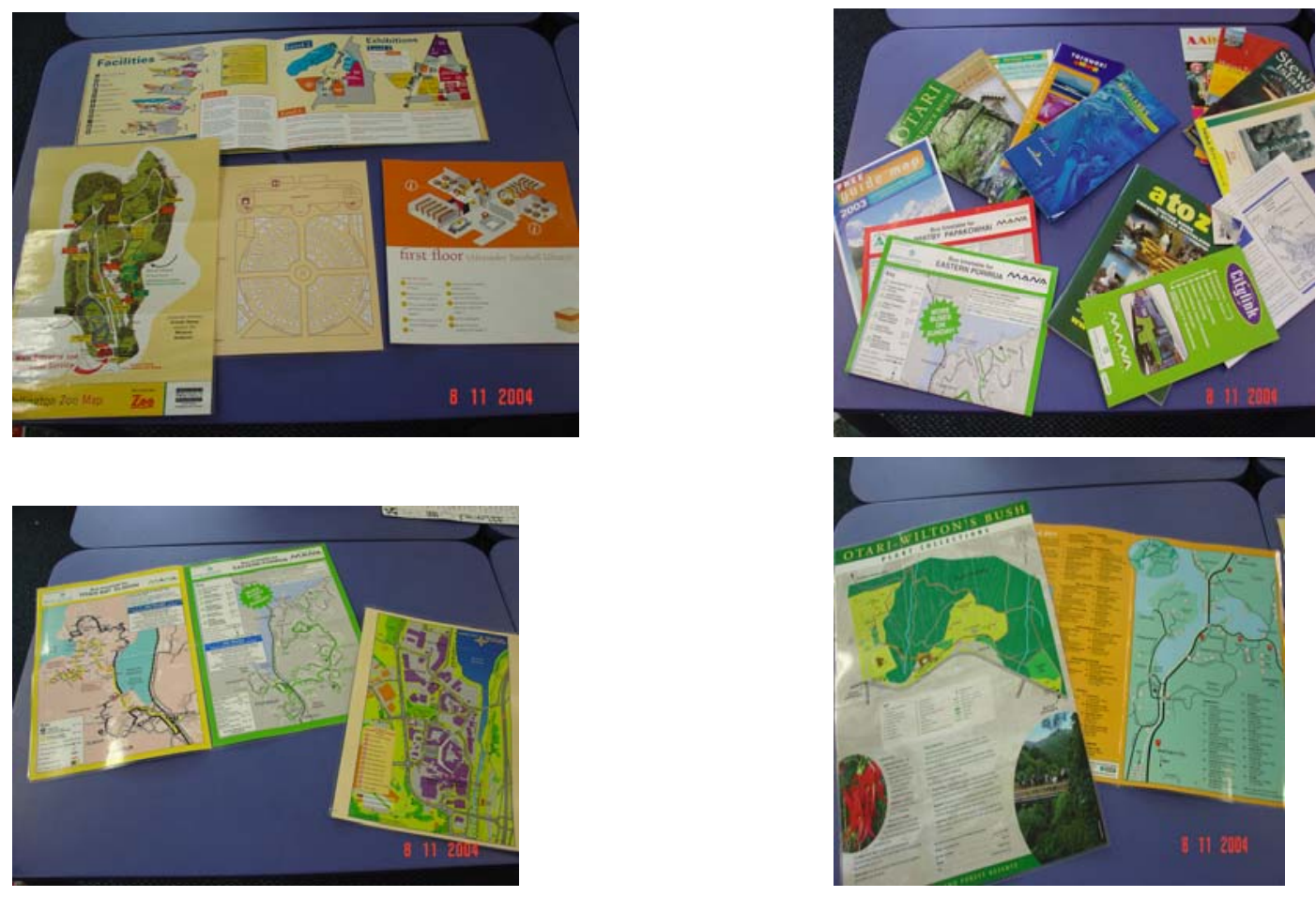

Figure 8: Collection of maps for using in the classroom 
The classroom programme started with the students drawing a map of New Zealand and placing the same locations on it as they had in first interview. Pam, the classroom teacher, then decided what she would teach from this.

Having collected the students' map drawings Pam decided what she wanted the students to achieve. She specifically wanted the students to:

- identify maps in their community.

- find things on a map including locations and symbols.

- Identify main geographical locations.

- Draw a recognizable map of New Zealand with North, South and Stewart Islands.

- Find countries on a world map or globe.

- Find locations they have been to in New Zealand.

Pam's major focus was to get the students to locate their home and places that their families came from. This involved looking at the islands in the Pacific and proved to be a difficult task when no suitable maps were readily available for showing all the islands at once in relation to New Zealand. This was of concern because she wanted to provide opportunities for all of her students to locate their origins on a map. Some of the maps she used were in texts like Blessing Yams in Niue (Wendt, 1987) or in School Journals (Learning Media Ltd). A lot of work involving atlases was based on the Philip's Atlas of New Zealand and the World (2003), as this was the atlas the school had purchased to use in the syndicate.

The language related to map reading was also an important feature of the teaching programme. Using mathematics as a context, Pam introduced the word "coordinate", the concept and its use. The knowledge gained from this was transferred to a game the students learnt to play. This game involved working with a buddy and an atlas. Initially the teacher chose a location to find. This role was transferred to the buddy once the students had mastered the activity. Pam chose a location and the students had to use the index in their atlas to find the page number and the map coordinates for the identified location. They then had to find the location on the map and describe the co-ordinates to the class. Each time they did this the language they used was reinforced and repeated. 
Other artefacts and concepts introduced and used throughout the unit included understanding about globes and atlases, using an index, maps, and a brief discussion about longitude and latitude. The relative size of maps was also discussed. Pam wanted the students to understand the notion of scale and that a large piece of land as they have seen it, will be a small dot on a page in an atlas or on a globe.

Pam challenged the students to record the route they took to school. To do this she photocopied the local street map, which she sourced from the local street directory and from the Internet at www.wises.co.nz. The students' task was to find their home and then to colour the journey they took to get to school. This proved to be difficult for the students who lived outside the area. To overcome this, Pam copied a group of maps and joined them together to show the whole area. From this, the class discussed what to do about bridges and how to represent their journey where the road either went over or under another part of road, and especially where there was a bridge or overpass. For the students who lived further away from the school, the motorway and an interchange were difficult features to represent, when tracing the route from home to school on their photocopied maps. For this Pam instructed the students to visualise the interchange and as a viewer, they were successful in identifying how the road should be shown on the map.

Every opportunity for learning about maps was used. In reading, specific reading texts and books, like The Map Book (Cutting \& Cutting, 1998), and The Key to Maps (Chan, 2001) were used with less able readers. For those who were more able, Pam used the New Zealand School Journals. From these, she chose stories and articles that featured maps or the opportunity to find locations. Examples included "A Letter to a Small Island (Journal, Part 1, No. 1, 2002) where a child writes letters to people in the Pacific to get stamps for a collection. Another was "Voyage to the Cold South" (Journal, Part 1, No. 1, 1994) which told of a young girls' voyage to Antarctica and featured the map below. See Figure 9.

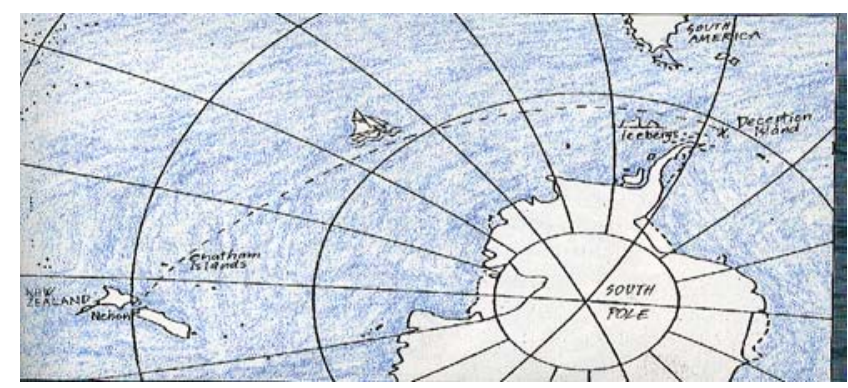

Figure 9: Journal Article map of Antarctica 
Maori Legends were also used, such as the story Te Ara o Kiwa (Journal, Part 3, No. $3,1993)$. This legend tells the tale of a whale who bit through land at the bottom of the South Island, thus creating Stewart Island and Foveaux Strait. Whenever the class read a story with places named in it, they consulted an atlas or the globe and located each place.

Another source of information was the weather page in the newspaper. Pam also encouraged students to talk about places they had visited. One student had travelled to Rotorua and had brought back a map. Pam reported how excited the boy was in finding this map, and being able to share it with the class. Other students began to notice maps that were in the community. They reported seeing the map of the local shopping centre on the wall and were able to use it to navigate their way around the centre.

In the unit the students learnt about the shape and geographical features of New Zealand. They discussed the three islands and named them on a poster-sized map of New Zealand. The main centres were located and the students also located their birthplaces if they were different from where they live now. Pam also used a map representing Maori tribal locations and the Maori names for the cities of New Zealand as part of a Te Reo link to the mapping unit. Figure 10 shows some of the artefacts used in the unit and that were also located in the classroom.
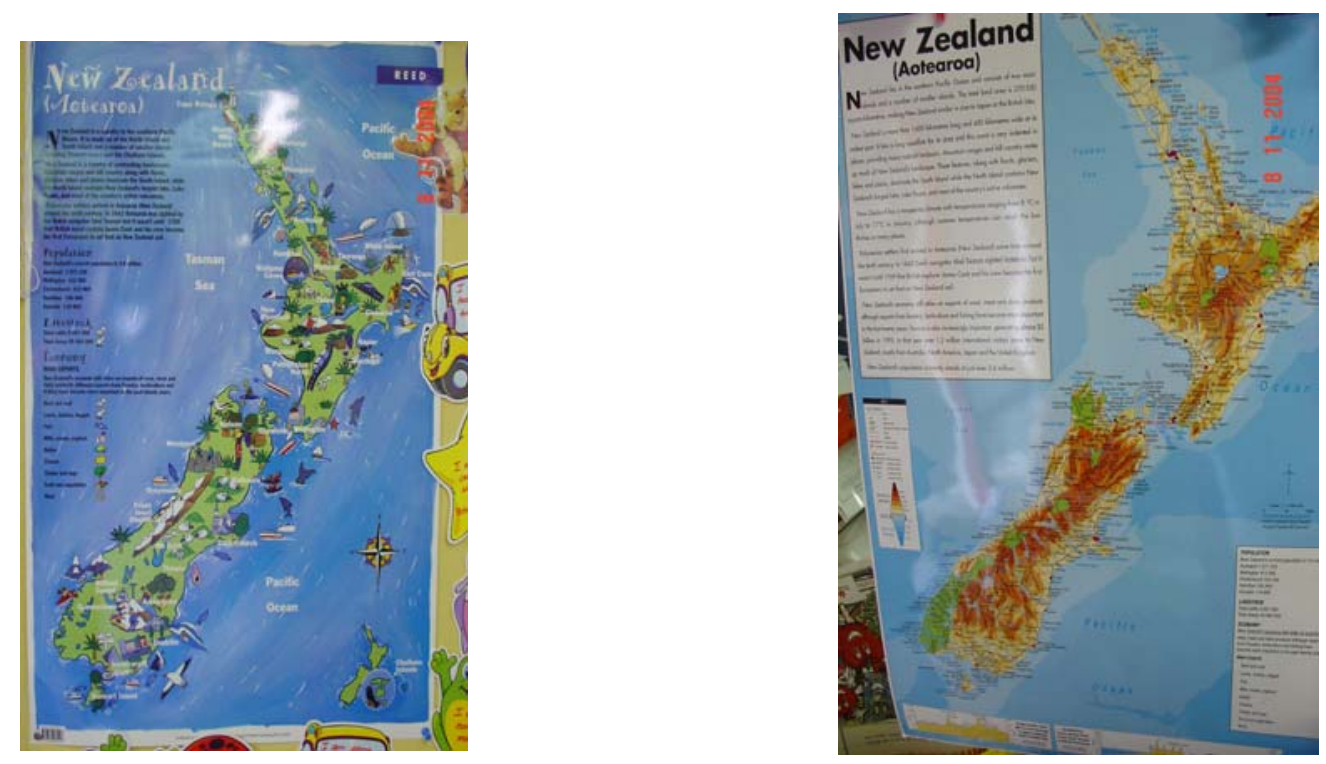

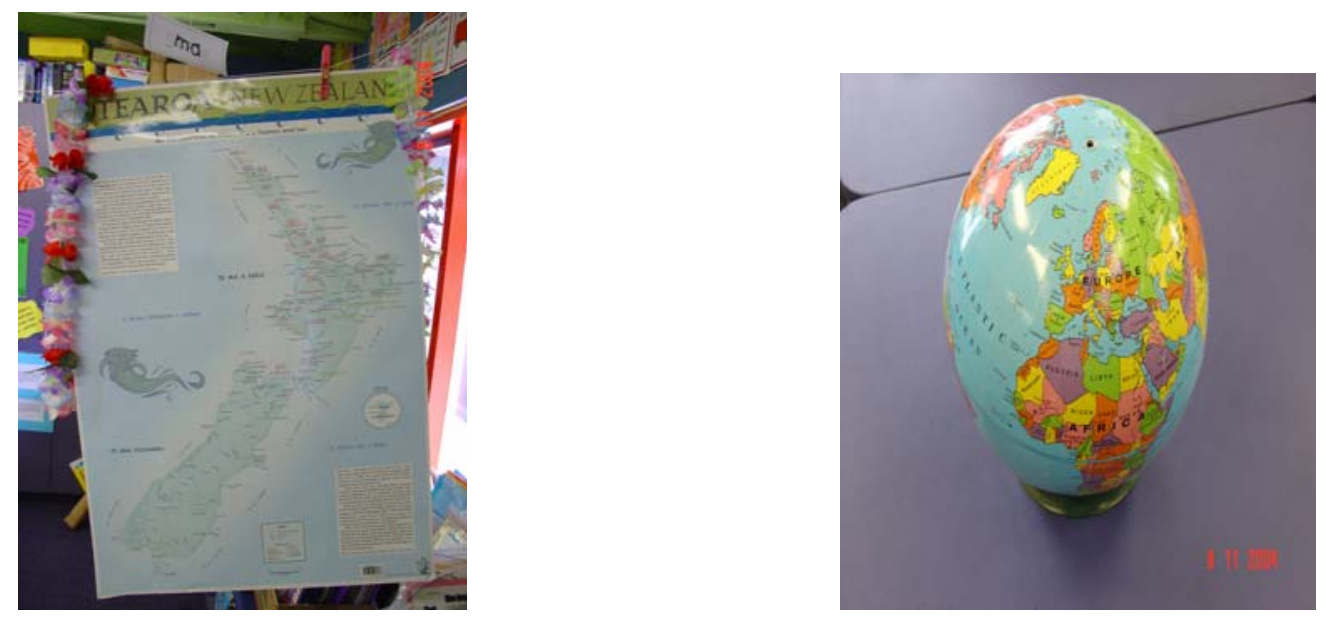

Figure 10: Maps and Globes used in the classroom

The intervention, a unit on maps, concluded with the students having the opportunity to draw their map of New Zealand again as part of the school wide assessment data gathering process. The unit took place over a three-week period. Each lesson varied in length depending on whether it was linked to Social Studies, Mathematics, Reading, or was part of a class discussion like those at news time each morning.

Pam reported that the students got a great deal of pleasure out of working with maps. In particular, they enjoyed being able to use the globes and explore where other places in the world were and they liked being able to use language associated with maps, like "co-ordinates". The most popular activity was finding places in an atlas. This activity was one that the students would do by themselves during free choice time or before school.

\section{Summary}

This chapter describes the intervention carried out by the classroom teacher. During the intervention the students were challenged to develop their knowledge about maps and where they could be located. Wherever possible, links were made to resources available in the school. 


\section{CHAPTER 9}

\section{Results: The Follow-up Interview}

After the intervention by the classroom teacher, the students were all interviewed again. The students were not asked to sort tables, graphs and maps but they were asked the questions relating to their knowledge of maps. Their responses are as follows.

What is a map used for?

Finding places in New Zealand - all over New Zealand anywhere. (Rachel)

To show you where places are. (Natalie, Trudy, Liam, Sally, Roger). This is a general response of the kind expected in schools. The other responses are more directly connected to home or the neighbourhood.

To help you to go to your friend's house. (Trudy).

Help you to go where you're supposed to go. (Sally)

Sometimes street maps show a street. (Natalie).

For finding streets. (Chris).

For if you needed directions if you're lost or if you're going somewhere and went the wrong way. (Karl).

These responses are similar to the responses given in the first interview. But this time the students believe that a map is used mostly for finding your way around either New Zealand or a street or for getting to a friend's house. Trudy's response remained unchanged from her answer given in the first interview. The answers represent the skill of using maps. The extension of use to finding places in New Zealand can be attributed to the intervention.

Where would you find a map?

Responses to this question were similar to those in the first interview. The students suggested that you could find maps:

In a map shop. (Rachel, Natalie).

At a shop. (Sally, Trudy, Chris, Karl).

In a place down under the house. (Rachel).

Might have put it in your bedroom. (Rachel).

On the shelves. (Trudy).

In a wardrobe. (Trudy). 
In cupboards. (Trudy).

In the car. (Roger, Trudy, Liam, Chris, Karl).

At your friend's house. (Trudy).

In a classroom. (Sally).

Outside the office - at school. (Sally).

On your cell phone if you have one. (Chris).

In books (local directory). (Roger, Karl).

In shopping malls. (Liam).

In parks. (Liam).

Rachel, Natalie and Chris all said that you could find a map at a "map shop" as compared with Trudy, Sally, Karl and Liam who knew you could get maps from shops but did not specify what kind of shop. The students also narrowed the range of places for getting maps. The key places from their responses are shops, school and home (including the car).

They were then asked to think about what reading a map meant.

What does reading a map mean?

Once again, this question required a definition and proved to be difficult for the students. Six of the eight did not answer. Of the remaining two, Natalie defined reading a map as "you can read a map". From this, one has to wonder what she understands reading it to be. Sally defined reading a map by saying, "that you're finding different places and learning where different stuff are". She also responded with a similar answer in the first interview.

Following on from this they were asked:

Can you read a map?

This produced a greater response rate and reflected what they had been taught in the intervention. All the students said they knew how to read a map. Trudy however, began with a sensible answer and then said she didn't know. Since most were unsure of what reading a map meant in the previous question, they were asked to describe how they would read a map. They responded with the following ideas:

Look up the co-ordinates and find places on a street map. (Sally).

I go to find the places where it's short and I don't get lost. (Rachel). 
Look at the first page and see if that's the place you want to go. I don't know. (Trudy).

Try to find the streets and parks. Try to find which place is safe for you and which isn't. (Liam).

You go to the index and the place you want to find and go underneath it and go to that page and look at the, I don't know what, like D5 or something like that. (Chris).

You read it by reading the streets and places. (Karl).

You can look in the index. (Roger).

I could look at the streets and I could see what's the name of the street. (Natalie).

Both Sally and Chris referred to using co-ordinates. Chris couldn't remember what they were called but he defined how to use them. Sally, Trudy, Chris and Roger also knew that you could use a book to find where you want to go. It could be a book containing maps and not necessarily an atlas.

They were then asked about atlases.

Can you tell me what an atlas is?

Six of the eight students knew that an atlas was a book of maps. Of the remaining two, Rachel started out by saying that "there's a big circle on the atlas. It's the whole world. It shows everywhere". She then followed that by saying that "It's got an index at the back". Clearly she has a better idea about what an atlas is and may well have been describing The Times Concise Atlas of the World (or some similar atlas) which shows the world as a globe on its cover. Trudy knew that that it was something that shows "where places are". Again, generally these differ from their original answers in Chapter 6.

What is it used for?

The students all knew that an atlas was for finding places. This included locating places in New Zealand and around the world. Having established that they knew what an atlas was, they were asked:

Do you have an atlas?

The students all had a much clearer idea about what an atlas was and whether they had one. All knew that they could locate an atlas at school. Liam said he had an 
atlas but it wasn't at home. Natalie said that she did not have an atlas but that she did have one at home. Chris remained unchanged with all his responses. Whereas Rachel, Liam and Roger changed all their responses from the previous interview. They were then asked about locating atlases.

Where would you find an atlas?

Rachel and Roger did not know where they could find an atlas. Rachel had stated in question six that there were atlases at school and that they were by the dictionaries. The other students all knew that they would find one either at school or in a shop. Trudy, Sally, Chris and Karl described the exact locations in their classroom. Liam said that you would find an atlas "in places where you can learn things". Table 7 summarises the result from the last two questions to show who reported owning an atlas and where an atlas might be found.

Table 8: Owning and Locating an Atlas

\begin{tabular}{|l|l|l|l|}
\cline { 2 - 4 } \multicolumn{1}{c|}{} & \multicolumn{3}{|c|}{ Atlas } \\
\cline { 2 - 4 } \multicolumn{1}{c|}{} & Yes & No & $\begin{array}{l}\text { Don't } \\
\text { Know }\end{array}$ \\
\hline Rachel & & 4 & \\
\hline Sally & & 4 & \\
\hline Trudy & 4 & & \\
\hline Natalie & & 4 & \\
\hline Karl & & 4 & \\
\hline Liam & 4 & & \\
\hline Chris & & 4 & \\
\hline Roger & & 4 & \\
\hline & $\mathbf{2}$ & $\mathbf{6}$ & $\mathbf{0}$ \\
\hline
\end{tabular}

\begin{tabular}{|l|l|l|}
\hline \multicolumn{3}{|c|}{ At Home } \\
\hline Yes & No & $\begin{array}{l}\text { Don't } \\
\text { Know }\end{array}$ \\
\hline & 4 & \\
\hline & 4 & \\
\hline 4 & & \\
\hline 4 & & \\
\hline & 4 & \\
\hline & 4 & \\
\hline & 4 & \\
\hline & 4 & \\
\hline $\mathbf{2}$ & $\mathbf{6}$ & $\mathbf{0}$ \\
\hline
\end{tabular}

\begin{tabular}{|l|l|l|}
\hline \multicolumn{3}{|c|}{ At School } \\
\hline Yes & No & $\begin{array}{l}\text { Don't } \\
\text { Know }\end{array}$ \\
\hline 4 & & \\
\hline 4 & & \\
\hline 4 & & \\
\hline 4 & & \\
\hline 4 & & \\
\hline 4 & & \\
\hline 4 & & \\
\hline 4 & & \\
\hline 8 & $\mathbf{0}$ & $\mathbf{0}$ \\
\hline
\end{tabular}

Table 7 shows that most students did not think they had an atlas or that one would be found at home. They were all certain however, that an atlas could be found at school. Having spent some time looking at maps and locating places in atlases at school, it can be concluded that the intervention played a part in developing the students' understanding of atlases and where they can be found.

\section{Do you use a globe?}

Five students said that they did use a globe. Rachel and Roger did not know and Sally did not think so. In the previous interview Rachel and Roger where unsure of what a globe was and Sally, along with the others, had stated that they didn't use a globe. 
The next question was:

How would you find your street in your town?

Don't know. (Roger).

Use a bus timetable thing or read the signs from those big maps. (Rachel).

Get a street map and you have to find [the city where you live] and you have to find places that's near it like [the street you live in] and find your street and where you live. (Chris, Sally).

Look in an atlas. (Liam).

By looking in a map. (Trudy, Karl, Natalie).

Trudy and Sally gave the same answer as in the previous interview. Roger had previously said, "using a map" but this time he was uncertain.

A city in another country?

I'll look at an atlas. (Natalie, Rachel, Sally, Liam).

Don't know. (Roger, Karl).

Looking in the index. (Trudy, Chris).

Look at a globe. (Sally, Rachel).

Both Roger and Karl's responses were the same as they gave in the first interview.

How to get to someone's place?

Look at co-ordinates. (Roger).

Reading the signs on the street things. (Rachel).

Getting a street map. (Chris, Trudy, Sally, Karl).

Don't know. (Liam).

Ring them and they'll tell you the number and the street and get an atlas and it tells you where to go. (Natalie).

Having not shown any idea of how to find a street in a town or another country, Roger has now responded with "look at co-ordinates" showing recall of something he learnt from the intervention.

\section{Discussion}

The answers given at the first interview were related to everyday activities involving maps and the students' own experiences of these. Some of these responses 
reappeared in the second interview. What distinguishes the second set of answers following the classroom intervention was that the students had learnt map reading skills using co-ordinates, and they had acquired some formal map vocabulary. In the second interview the students often used language relating to mapping. When asked about finding locations they referred to looking in an atlas, using the index and looking at a globe. When reading a map Sally used the term co-ordinates and Chris could not remember the term but said "look at the I don't know what, like D5 or something like that". They knew more about map resources and that they were objects located in schools. All eight students had found out that there was an atlas at school. The students were more specific about what maps were and what one might be used for. They also knew that an atlas was a book of maps and five had used a globe.

The second set of answers raises questions about the use of a brief questionnaire to tap what the students had learnt from a focus on maps over a three-week period. It was obvious that in some instances students knew the answer but did not supply it. Did they realise that the interview questions were seeking meanings which may have been presented to them in the classroom? Did the students relate a particular form of question to the way in which maps had been presented by their teacher? What would the answers have been if the teacher had asked them, or if the interviews had been carried out in the classroom with the resources available for them?

The students did far better explaining the practical use of maps than they did in answer to the abstract question about what it means to read a map. On the other hand the questionnaire in both the first and second presentations tapped knowledge about maps and their use, knowledge which had come from the home and neighbourhood. What the questionnaire was able to show was how the intervention had increased the students' previous understanding of maps and their uses.

\section{Summary}

These students had some information about maps gained from home and neighbourhood but intervention from the classroom teacher provided the children with technical knowledge. The students were all exposed to the same information throughout the unit and they clearly gained knowledge about maps from their teacher and also from maps in the school environment, especially those in the classroom, syndicate and library. The school had map resources, as shown in the illustrations in this chapter, beyond the resources of a typical family. 
The students were asked to draw a map of New Zealand again and to place the same locations as they were asked to do in the first interview. In the next chapter the results are shown for each student. 


\section{CHAPTER 10}

\section{Results: Sketch Maps}

This chapter will show the results of the map drawing from both the first and second attempts to draw a map of New Zealand. The second drawing came after the classroom intervention.

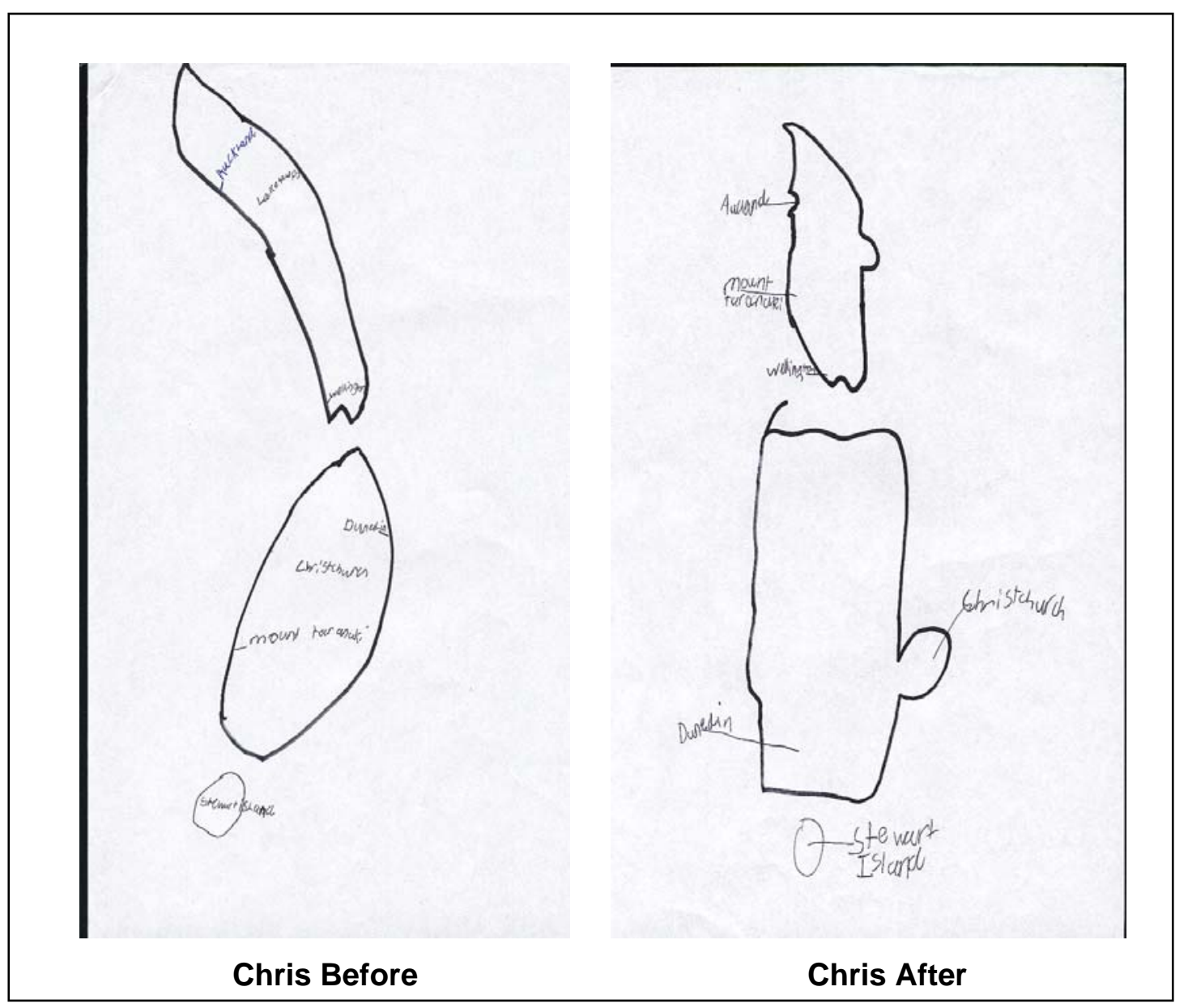

Figure 11: Chris's Drawings

In these two drawings, Chris has developed the shape of the islands. In the second drawing he has added the peninsula pieces on the eastern side of the country. He had also managed to place the locations more accurately. 


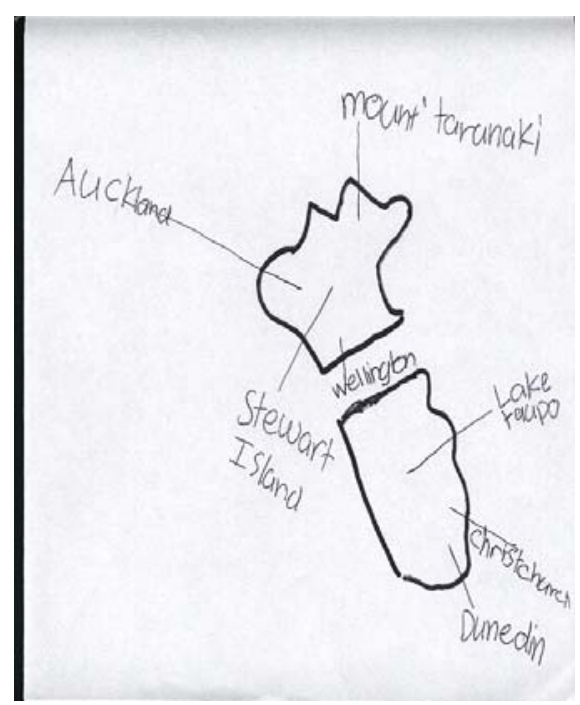

Karl Before

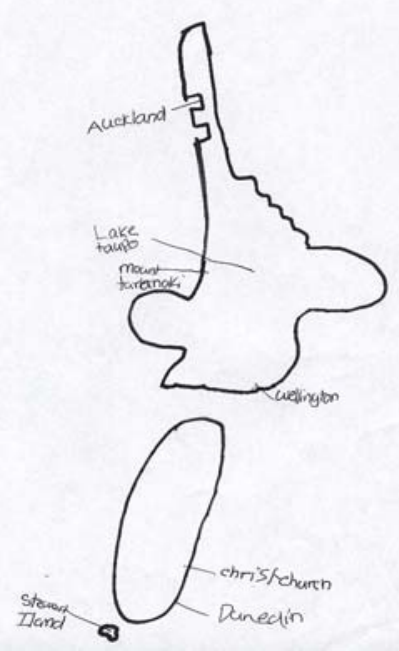

Karl After

Figure 12: Karl's Drawings

Karl had made some major changes to the locations and placement of his map. In his first drawing New Zealand sloped to the left and the North Island was incorrectly shaped. He has managed to get the shape of the North Island in his second drawing along with the correct placement of locations.

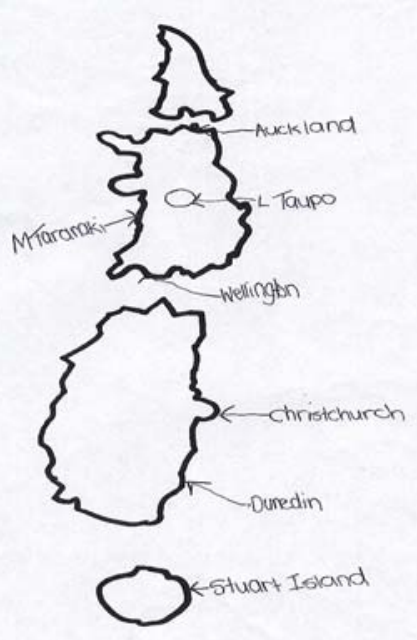

Natalie Before

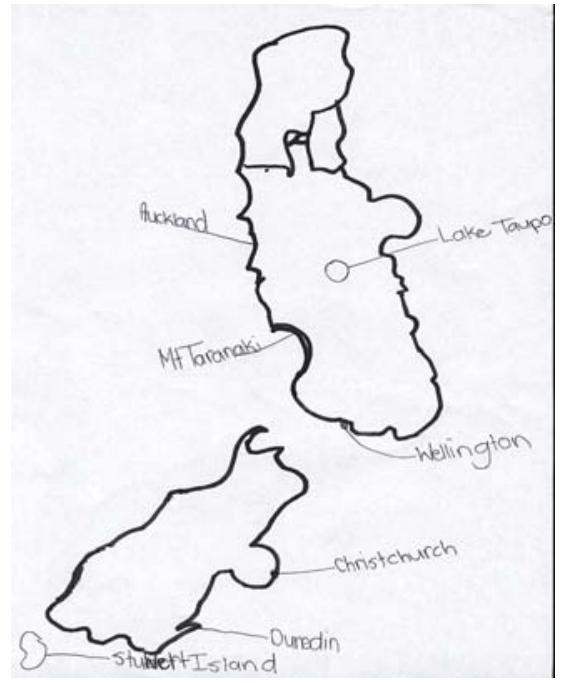

Natalie After

Figure 13: Natalie's Drawings 
Natalie has had some difficulty in getting the shape of the North Island correct. She managed to correctly place the locations in both drawings and has also managed to make the shape of the South Island more correct. It was not until she was placing the locations on the map that she remembered to draw Stewart Island in the second drawing.

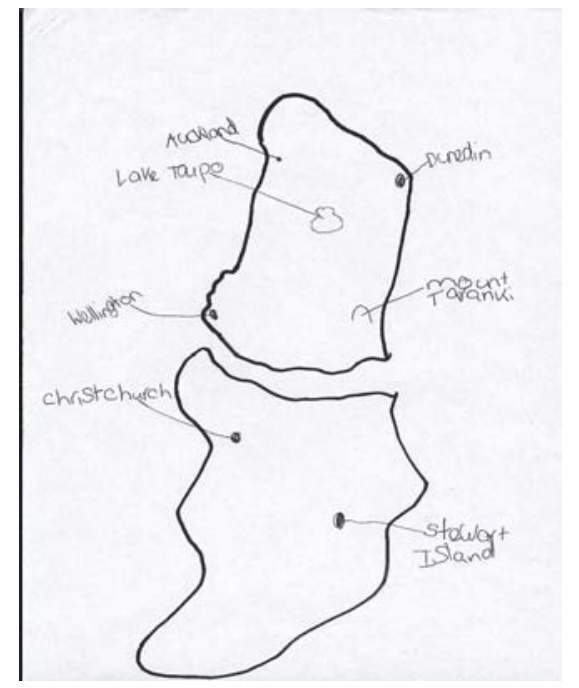

Sally Before

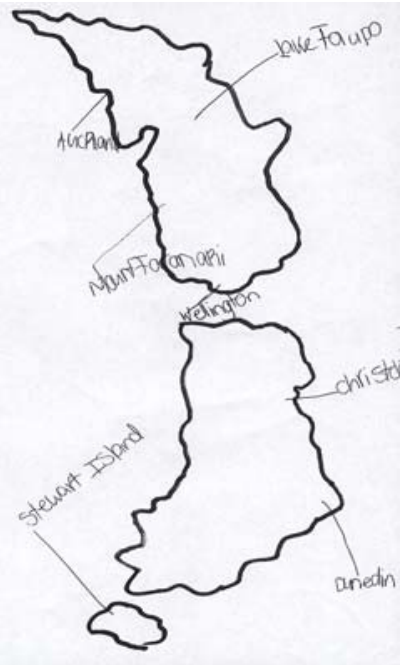

Sally After

\section{Figure 14: Sally's Drawings}

Sally has managed to get all three islands in her second drawing. She has shown the correct location for each city in her second drawing also.

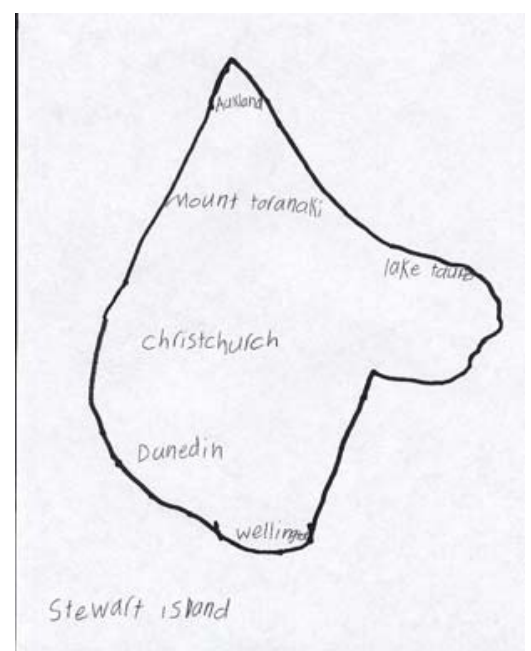

Roger Before

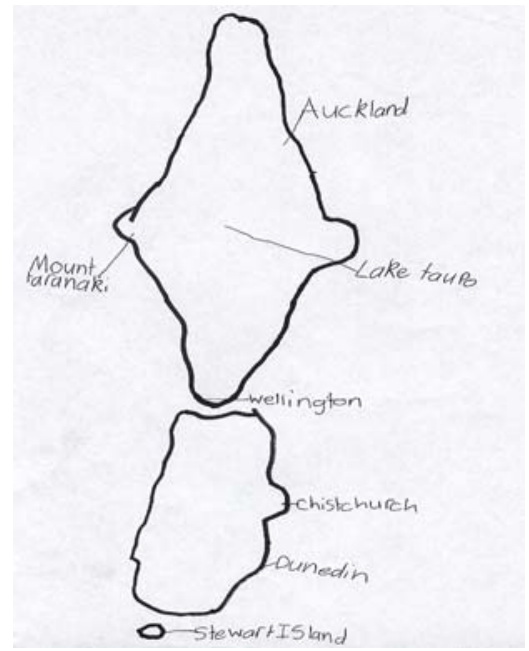

Roger After

Figure 15: Roger's Drawings 
Roger has made some major changes in his thinking about New Zealand. In his second drawing he has drawn three islands and placed the locations on them correctly. This is a huge shift from the one island he previously drew with Stewart Island in the middle of nowhere.

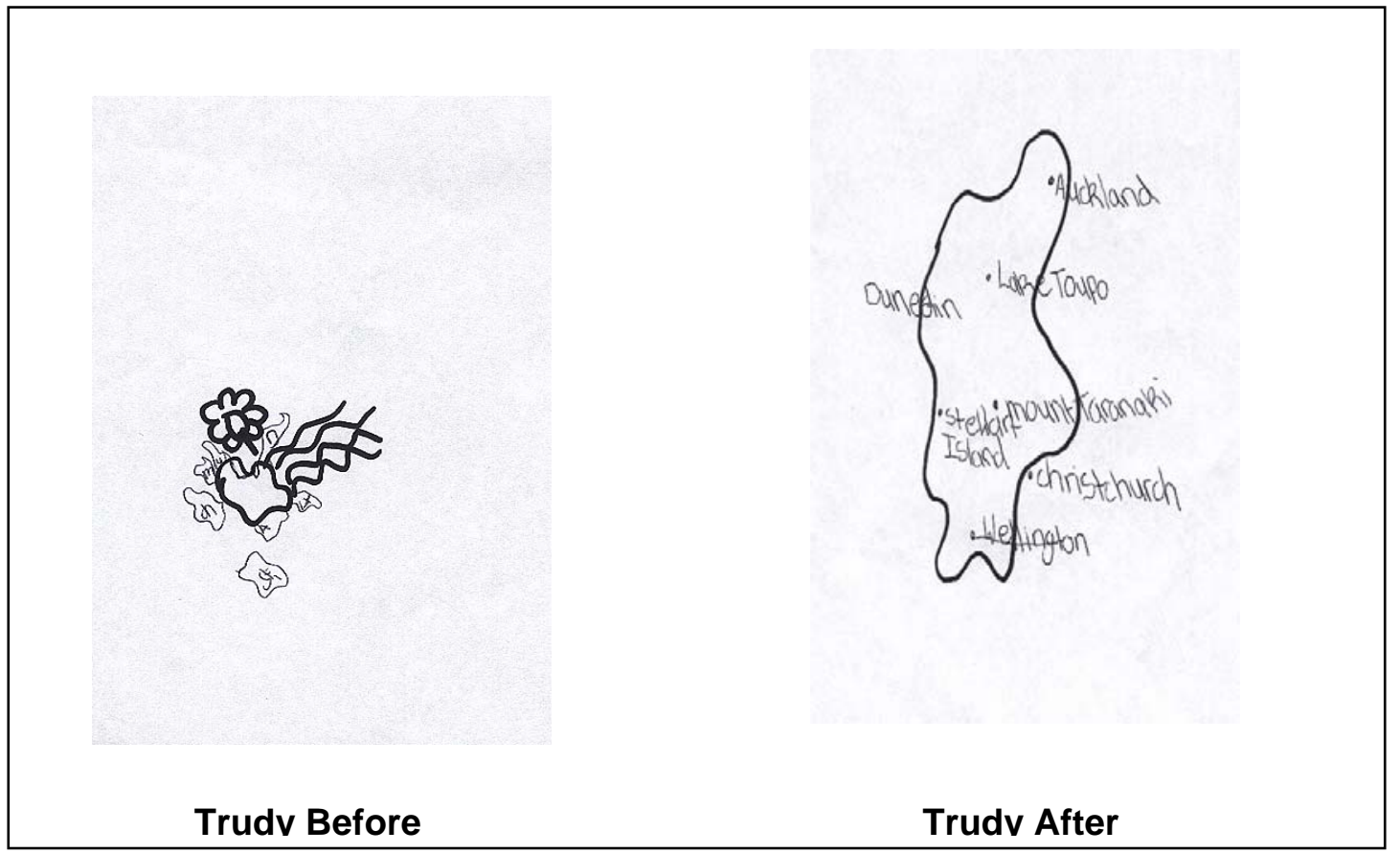

Figure 16: Trudy's Drawings

Trudy's maps, while not accurate, show some changes in thinking. In her first map, she has used flowers and squiggly lines to represent roads and has drawn in locations around this. Her second map moves away from this and shows one island containing all locations. She shows some understanding of cities being in different parts of the island, but does not quite get them all correct in terms of the order of their placement.

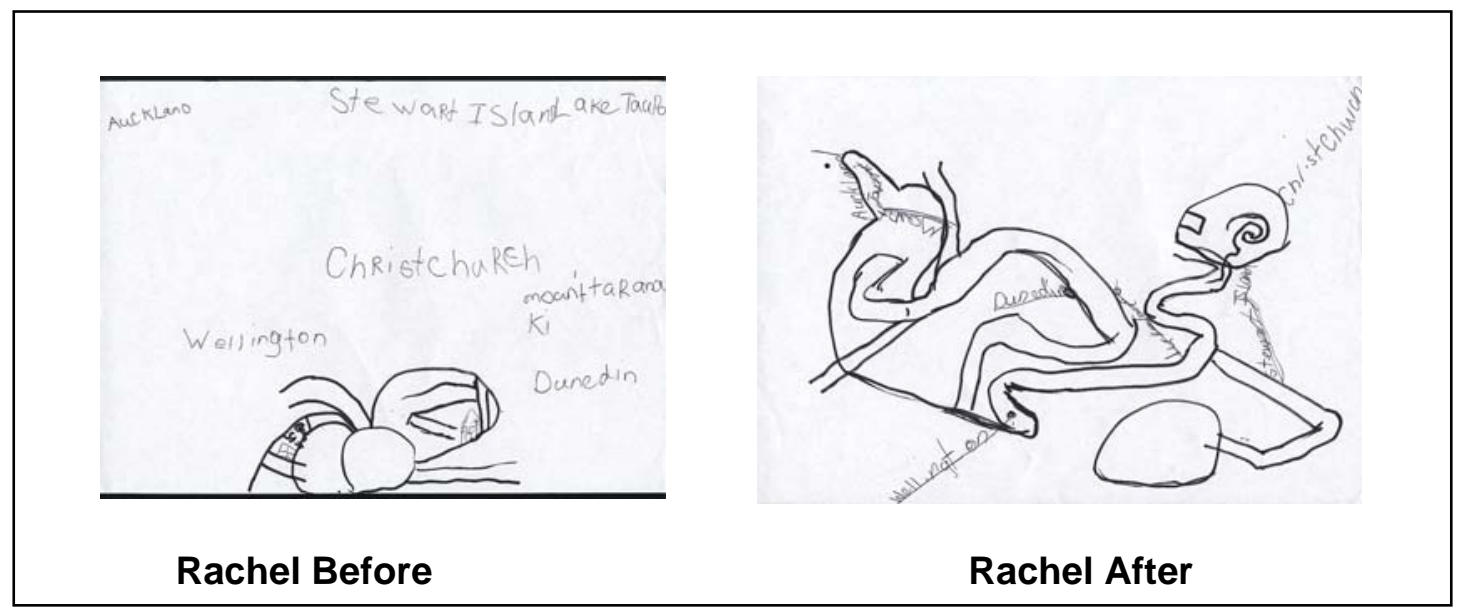

Figure 17: Rachel's Drawings 
Rachel's are perhaps the most interesting of all the maps. Rachel had a great deal of fun drawing them. She talked to herself as she worked and told of the things in her maps. Her first map shows her house and the bus stop. Each group of lines represents the roads around the area where she lives, and the other locations in New Zealand have been placed out on the rest of the page. This represents all the other cities being outside her world and being part of a big place she's heard of. In her second drawing she has attempted to link the locations to the roads that have been drawn. The spiral near Christchurch is a round-a-bout and her house is near this.

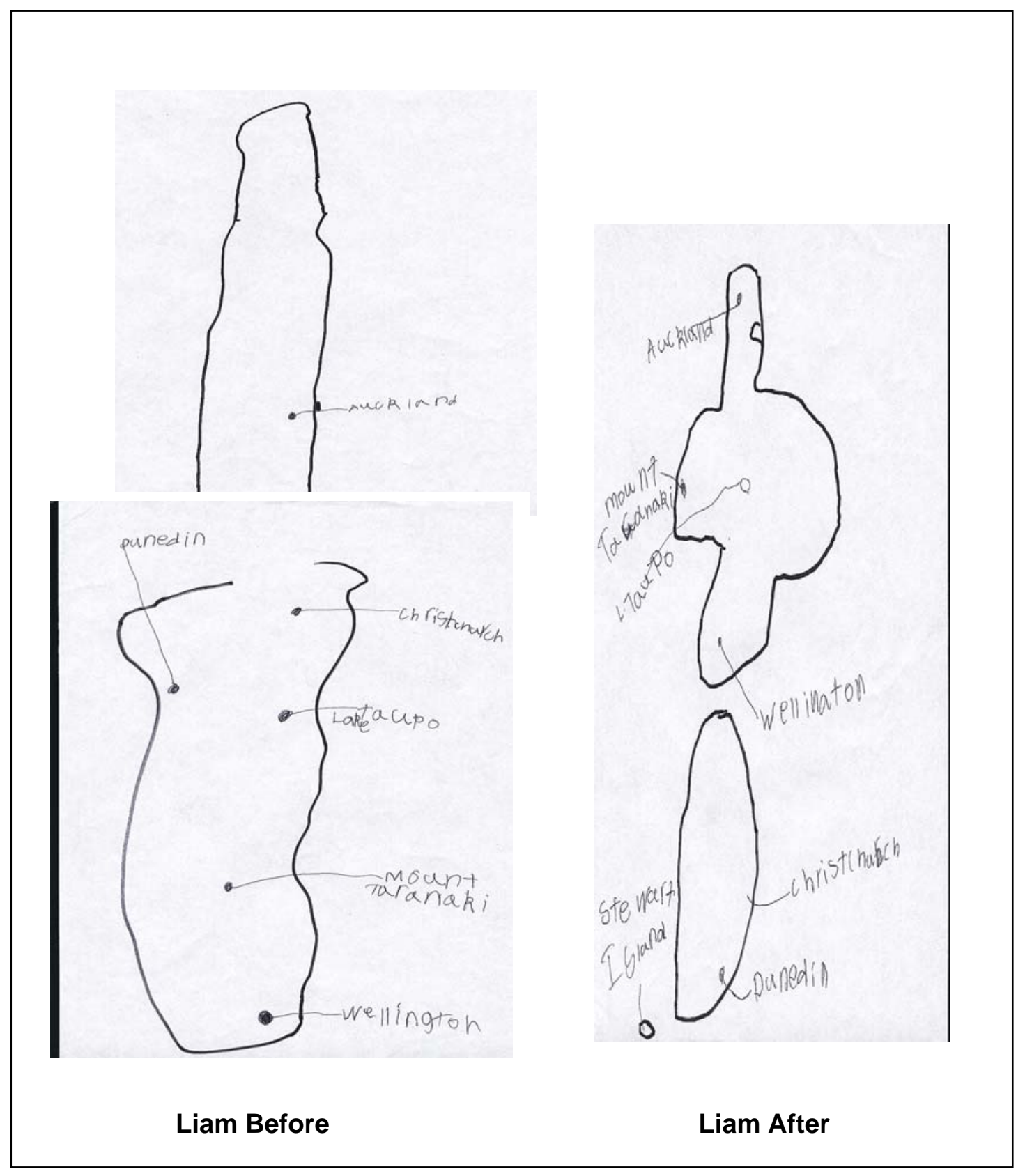

Figure 18: Liam's Drawings 
Liam chose to use two pieces of paper for his first drawing. When asked to show exactly how his map worked he placed the upper piece directly over the gap on the lower piece. This made the shape of an island resembling the shape of the North Island. He then placed the locations on his drawing. In his second attempt he shows a clearer understanding of New Zealand being made up of three islands and has drawn this. He has also managed to correctly place the locations on his map.

The results are summarised below using the same scale as for the first attempt.

Table 9: Final Shape and Proportion of the Islands

\begin{tabular}{l|c|l|c|l|c}
\hline \multicolumn{2}{c|}{ Islands } & \multicolumn{2}{c|}{ Proportions } & \multicolumn{2}{c}{$\begin{array}{c}\text { Shape and relative } \\
\text { positions of the islands: }\end{array}$} \\
\hline 3 main islands & $\mathbf{6}$ & About right & $\mathbf{2}$ & Approximately correct & $\mathbf{3}$ \\
2 main islands & $\mathbf{0}$ & North Island too large & $\mathbf{3}$ & Good attempt & $\mathbf{3}$ \\
Other & $\mathbf{2}$ & South Island too large & $\mathbf{1}$ & Little resemblance & $\mathbf{2}$ \\
& & Not applicable & $\mathbf{2}$ & & \\
\hline
\end{tabular}

Placement of locations:

Table 10: Final Placement of Locations

\begin{tabular}{lccc}
\hline Locations & $\begin{array}{c}\text { General area in } \\
\text { correct island }\end{array}$ & $\begin{array}{c}\text { Correct island, } \\
\text { but misplaced }\end{array}$ & Incorrect \\
\hline Auckland & 5 & 1 & 2 \\
Wellington & 6 & & 2 \\
Christchurch & 6 & 1 & 2 \\
Dunedin & 5 & & 2 \\
Mount Taranaki & 6 & 2 \\
Stewart Island & 6 & 2 \\
Lake Taupo * & 5 & 2 \\
\hline
\end{tabular}

* One student did not include Lake Taupo on their map.

Roger showed the most improvement having previously drawn a single island and then drawing three. While Trudy and Rachel remained in the "other" category, both showed improvements in their understanding of what maps might look like. Trudy moved from drawing an abstract shape to having one island. Rachel expanded her idea of roads and places of interest. 
Drawing New Zealand is not an easy task and these students had to carry out this task from memory. Their second drawings show some of the details they observed and remembered from the intervention. Chris has got the general shape of Banks Peninsula in his second drawing. Karl and Roger, to a lesser extent, have got Taranaki and Hawke's Bay represented on their maps. Karl has also attempted to include Manukau Harbour. Natalie has the closest likeness to the South Island. Her drawing includes her recall of Farewell Spit. She also shows that the two islands do not go in a straight line.

\section{Student Responses}

The students were asked to explain their drawing once they had completed it. Their responses include:

It's got all places and I drawed a map of New Zealand and I drawed Auckland and Wellington and Christchurch. (Rachel)

My map shows that Stewart Island is there. (Chris)

It shows Dunedin, Christchurch, Wellington and Stewart Island. It's not a street map and doesn't show Porirua or Blenheim. (Sally)

Liam refused to give an explanation about his map. It can be seen from the explanations given that Sally has some knowledge of street maps and is able to differentiate between a street map and the one she has drawn.

The students gave the following explanations for the placements they made:

I think they go where I put them. (Rachel)

I know where Christchurch is because I've seen it on maps. (Natalie)

Because that's where I see them in my head. (Karl)

That's where I think they go. (Roger, Chris, Trudy, Sally)

I've seen them on maps. (Roger)

Because that's where they go. I don't know why. (Liam)

The students were quite certain that they had made the correct placements. Natalie also made reference to having seen Christchurch on a map. However, it is often difficult for children to explain where their ideas come from and, like Karl, the source may be recognised only as "in my head".

\section{Discussion}

All the students made improvements in their second map drawing. While the proportions of their maps remained the same, there was some improvement in the shape and relative size of the islands. The biggest improvement can be seen in the 
number of islands drawn. Prior to the intervention only one student drew New Zealand with three main islands. Two students drew only two islands. Following the intervention, six students drew three main islands. In their responses the students were prepared to state that they were certain of locations and their placement. They also referred to having seen maps or recognised that their map was not a street map.

\section{Summary}

This chapter showed the maps drawn by each student before and after the intervention together with their comments on their work. 


\section{CHAPTER 11}

\section{Conclusion}

In The New Zealand National Curriculum Framework (Ministry of Education, 1993) maps are classified as skills along with tables and graphs. They have been assessed three times by NEMP in 1995, 1999, 2004 and the Education Review Office looked at the quality of teaching about maps, tables and graphs in 2004. Information from the NEMP studies of 1995, and 1999 provided a starting point for finding out about what children might know about maps. In Panckhurst's (1989) study of preschool children she looked at maps in the home including not just the commercially produced cartographic variety, but more transient ones such as those displayed in television, in newspapers and magazines, and as toys and reproduced on maps for the floors of children's bedrooms. She also looked at maps that are on public display, and in neighbourhood settings. Hardie (2000) explored children's language and explanations of the world around them. She found that many children used maps and globes at home and that they were familiar with atlases and globes in a school setting. Apart from these studies there has been little research on the topic of New Zealand children's understanding of, and use of, maps and where their understanding comes from. However, Rowena Taylor of Massey University College of Education is producing a study guide about maps for students to use during their teacher training. This will draw on overseas as well as New Zealand research. Also a recent article (Bulman, Cubey, Mitchell \& Wilson, 2005) has described how children in a playcentre drew maps and used them to find treasure.

When the teachers in a junior syndicate in a Decile 2 school decided to teach a unit on maps this gave me the opportunity to make a study of students' map understanding before and after the unit had been delivered.

This study set out to address three broad questions:

1. What do young school children know about maps?

2. Are young school children familiar with the map of New Zealand?

3. What do they gain from learning about maps in the classroom? A research sample was selected from a Year $3 \& 4$ (age 7-8) classroom. This group comprised eight students: four Maori and four Pacific Nations: 4 girls and 4 boys. 
The curriculum classifies maps with graphs and tables, and these have been assessed together in the NEMP studies. Before my sample of students had experienced the unit on maps they were withdrawn from the classroom for a session in which they did three things: they were asked to sort some pictures of graphs, tables and maps and place them into their correct categories. The results showed that they had a familiarity with maps and their use that they did not have with graphs and tables. Since they had not been taught about maps in school, the most salient sources of understanding seemed to be the home and the neighbourhood.

Each student was then asked a set of questions about maps, globes and atlases, where they might be found, and what they might be used for. The results confirmed that the children were aware that there were generally maps in homes and places like shopping centres and nature reserves. Students were familiar with maps that would help you to drive to someone's place. They knew less about atlases and globes but in their talk about maps they knew that they showed you "where to go".

The final task was to draw New Zealand and place seven specific locations on it. On this task, performance varied from some understanding that New Zealand consisted of islands, to maps which looked like reproductions of the streets in a student's neighbourhood. Conventions such as recording the names of places within the outline of the map were not always displayed and there was little sense in the maps of the idea of scale.

Once the interview had been completed the three classroom teachers in the syndicate set about teaching their classes about maps. The children in my sample were taught by their own teacher who, over a period of three weeks, taught maps across the curriculum as described in Chapter 8 . The teacher introduced a number of resources and activities, involving the library and areas in the syndicate as places where maps are kept (see resources used in Figures 9-11). They also mapped their journey from home to school.

At the end of the intervention, the children were interviewed again in the same location. This time they answered a selection of the questions and carried out the same map drawing task. Their answers to questions about locating maps in homes were little changed but they were more knowledgeable about where atlases and globes might be found and their use of map language had become more technical. 
Their drawings of the map of New Zealand showed improved understanding of the conventions of mapping and a greater sense of scale.

The answers to the research questions will now be addressed.

What do young school children know about maps?

At the time of the study the students had not experienced formal teaching about maps. However, it was apparent after the first interview that the students all had some idea about what a map is and their performance on the task of sorting maps, tables and graphs into categories showed that they could distinguish both topographical maps and route maps much more accurately than they could identify tables and graphs. In sorting the representations into categories they were $85 \%$ correct in their selections of maps and the girls were also more successful than the boys.

The students were also familiar with route maps and in the initial interview Natalie and Liam explained them as showing "where to go", using informal map language about their use. The topographical map (map S) shown to the students after the initial sorting task, proved more difficult for the students to identify. The maps presented to the students had symbols on them. Some of these symbols showed huts. Most of the students were uncertain about how you might use such a map but suggested it could be used to locate toilets, an indication of a use that had probably been experienced in the past.

When the students were asked about where they would find a map some thought initially that you could buy one, suggesting shops as a familiar site where things could be found. Karl and Trudy suggested they would find a map at home. Others suggested looking in books, at the library or on the Internet, all of which are sources of map information. Roger, Trudy, Liam, Chris and Karl knew they would find one in a car. It is interesting to note that all the boys thought of a car as a location but only one of the girls did. Chris gave further suggestions, stating that you'd find a map "on your cell phone if you have one".

Just as Panckhurst (1989) found, two students (Sally and Liam) knew that maps could be found in "shopping malls, in parks". Panckhurst's children were not yet at school. In my sample, students reported that a map could be found "outside the office at school". But none of the students commented on the weather maps seen 
each night on television news bulletins. It was obvious from the students' answers to the interview questions that their experiences came from sites such as the home, the car, the shopping centre and recreational parks and that their understanding came from observation of, and participation in, activities associated with these sites. Although some had clearly overheard discussion such as "how to get to auntie's and Mum's friend's house" (Trudy), there was no indication that the students' information came from what parents or others in the family had deliberately set out to teach them about maps by explaining their use. While it is difficult to determine whether direct teaching about maps happened in the home, the informal sources of learning can be contrasted with the methods of the school where explanation is central to teaching.

\section{Are young school children familiar with the map of New Zealand?}

It became apparent as the students carried out the task of drawing an outline of New Zealand that the shape was very difficult for them to draw. In fact, many adults would no doubt have difficulty. The students needed knowledge not only about the general shape of New Zealand, but also the number of islands and their spatial relationship to each other. Thus, in the analysis, the focus was on the general shape and whether the students had the correct number of islands, and the correct placement of the locations.

All the boys produced drawings that were recognisably maps but in their first drawings Rachel and Trudy drew complex drawings that contained roads. They both placed the specified locations outside their drawing, indicating that the places were "out there, somewhere, like other countries". While all students had become more skilled in reproducing the general outline, number of islands and locations, they also made individual responses and Stewart Island produced variations. Karl was the most accurate with his placement of Stewart Island. Roger had one island with just the words to represent Stewart Island but in his second drawing he drew the island itself.

After the classroom intervention, in which the students had exposure to a variety of maps, Rachel and Trudy's drawings became more elaborate. Trudy moved on to having one island with all the locations within it while Rachel placed her locations along roads, but not outside her drawing as before. The others all placed their locations in the correct vicinity indicating that exposure to maps in class and practice in drawing the map of New Zealand had increased their understanding of places and their recall of locations. 
What do they gain from learning about maps in the classroom?

The students all showed gains in their knowledge and understanding about maps. The most interesting finding was the change in their use of map language between the first and second interview. While originally being uncertain about maps and atlases, they were more familiar with them and could explain what they were and how to use them.

In the first interview the students linked their ideas about reading maps to reading in general as experienced in the school setting. They knew that you had to look in the index or glossary. Sally had suggested that you "have to look/find lines of places just like any place of New Zealand and it will have a line to show where it is", showing a general understanding, possibly of grid lines defining areas or longitude and latitude on world maps. However, in the second interview she used the word "co-ordinates" when she said that to read a map "you look up the co-ordinates and find places on a street map". Chris said that "you go to the index and the place where you want to find and go underneath it and go to that page and look at the, I don't know what, like D5 or something like that".

\section{Classroom Intervention}

During the intervention stage the class explored maps. To do this Pam provided a variety of maps that were available in brochures, from atlases, the globe, large wall maps, street directories and from the Internet (See illustrations in Chapter 8). She used every opportunity to make links to maps. On one occasion this occurred during news time when a student shared a map he acquired while on holiday. The class were then given the opportunity to find where he went by using an atlas. A similar opportunity arose at reading time when a location was named in the text. The classroom teacher reported the excitement the students showed in being chosen to find places in the atlas or to use the globe. When giving directions Pam chose to use words such as "north" or "south" and illustrated their use. The children then used this knowledge to move in different directions when looking at an atlas. More specific language terms such as latitude and longitude were also introduced.

During the unit Pam noticed an increased interest in maps. The children began to choose an atlas to look at for silent reading. They also pointed out maps they had seen while on family outings. Most of all they loved a game she introduced in which the students had to locate a place and try to be the first person to find it. They would 
describe locations to their peers and were excited about being able to use their newfound skills. These changes in the students' behaviour were evidence that the skills taught in the classroom had an impact on the students' understanding of maps and how to use them.

Although quite young children are able to draw route maps, they are unable to differentiate between the size and proportion of objects. Often their drawings have intricate details for roads and one or two large buildings that represent houses. It can be difficult for young school children to understand representations of geographical space. The ability to draw a map is not necessarily an indication of spatial awareness but comes from observing maps as representations. This is supported by Welton and Mallan (1996) as discussed in Chapter 3. The maps of New Zealand drawn by the students showed that they had some difficulty getting the elements of the map into their proper spatial relationship. Children also find the concept of "birdseye view" difficult as they do not get many opportunities to look down on their world. Using the globe in the classroom confused some students who were used to looking at a flat representation of the world in an atlas and they all had difficulty explaining what a globe was when asked in the interview.

\section{Maps, Tables and Graphs}

These three visual artefacts are linked together in the New Zealand Curriculum. The Education Review Office (2004) links graphs, tables and maps and states that "competence in the use and interpretation of graphs, tables, and maps is included within international studies as a key component of literacy" (Quality of Teaching in Years 4 to 8: Graphs, Tables and Maps. p. 3). The International Adult Literacy Survey (IALS), which is quoted in the Education Review Office report, identifies graphs, tables and maps as being in the category of "document literacy" (p.3). However, the research reported in this thesis showed that the students did not see the three as related and that they were far more familiar with maps than with tables and graphs.

The incorporation of maps with tables and graphs as "essential skills" causes no difficulty for evaluating performance on all three as in the NEMP studies. However, they are taught in different areas of the curriculum and by different methods and they mean different things, making it difficult to judge the teaching of all three together as the Education Review Office has done. In teaching statistics for example, more emphasis is placed on graphs than on observing or creating tables. 
While knowing about the links between graphs, maps and tables, it is important that students first learn to interpret each one separately and to understand the information that is embodied within each category. Maps however, require different skills and have different rules for interpretation.

Tables and graphs, unlike maps, are hard to link to a Pacific homeland and do not readily lend themselves to literary works. Maps have a history, they may have artistic value, and they teach us about the environment, about politics and national boundaries.

The students in the study were aware of what maps are and they were able to identify features on maps with the support of the classroom teacher. Strategies she introduced allowed the students to investigate maps and explore the world using either an atlas or a globe. She also incorporated literature into the mapping unit. Wherever possible, links were made to maps that featured on the page. Some were obvious and others less obvious. Reading texts such as The Map Book (Cutting \& Cutting, 1998) allowed the classroom teacher to provide opportunities to explore the use of maps directly. The students could see and use maps as they read. Another learning opportunity from the reading texts was that the students each took the books home as part of their home reading programme and so other members of the family could explore and discuss the use of maps, thus providing a link between what was taught at school and increasing the use of map related language at home. They also learnt specific map language such as the terms "key" and "symbols". The students' knowledge of maps could then be linked to other texts such as being able to identify the map of the world in The Waterhole (Base, 2001) as the rain creates puddles that form the shape of the world.

The intervention gave the students a heightened awareness of maps and where they can be found. They were able to locate places within New Zealand and some could find places around the world. They could also recognise maps in the newspaper, on television, perhaps as part of the weather or on the news. However, specific teaching had to occur for these students to identify the features of maps and for them to be able to use maps with confidence.

The family and neighbourhood allowed the students to observe the use of maps, especially route maps, and it appeared from the students' reports that they had been 
involved in activities using maps. They did not appear to have gained experience of tables and graphs from family or neighbourhood.

Maps are cultural artefacts with much wider meaning than tables and graphs. Above all, as the classroom intervention showed, young school children get great pleasure from learning about maps and particularly from using them.

\section{Discussion}

The design of this study made it possible to separate out informal map learning and its sources in family and neighbourhood from the learning that takes place in school. Because maps are often used in homes, learning about maps in school may feed back into family knowledge. The presence of maps in the neighbourhood suggests that students could make an inventory of maps and explore their method of presentation and their purpose.

The study described in this thesis involved young school children. The NEMP studies involved older children and showed gains in map knowledge between Year 4 and Year 8. A further topic for research might be about the processes in school, family and neighbourhood which produced these gains.

Students' understanding of the purpose of maps as "finding out where to go", the navigation function, came through very strongly. The concept of navigation could be pursued by means other than maps of the land. There is navigation by the stars and navigation over land by landmarks and measurement of distance.

Although this study did not explore gender difference it is an area that deserves investigation. Are boys more interested in maps than girls? Is it the boys who seek the atlases in the classroom or the library? Is this something that could connect boys to literacy?

\section{Postscript}

Throughout the intervention on maps, I was teaching my own Year $2 \& 3$ class in the same syndicate. My experiences of what the students knew about maps was similar to those that Pam found in her classroom. With my own class, I was able to capture the students' interest through literature that demonstrated different perspectives about mapping. 
One idea I addressed was the notion of "bird's-eye view". I felt that by introducing the students to this concept, they would be able to look differently at the maps presented to them and have some idea of perspective. Many of the students in my class thought I travelled from a different country each day. On a syndicate trip into Wellington, later in the term, the students were able to visualise the route while travelling on the bus and then look at the same route on a map the next day.

Like Pam's class, my students all enjoyed being able to use the globe and atlases. Some would name a country and then challenge a buddy to find it on the globe. They would give clues like "it's on the other side of the world" or "it's a pink country" referring to the colours of the countries in both the globe and atlas.

My own awareness of maps was heightened throughout the unit. I became more aware of places students might view maps. I was also aware of how much of a map they may see. This was especially so on television during the news or weather where only a portion of New Zealand was shown. More recently, weather forecast presentations appear to have changed and now include a sweeping view of all of New Zealand, although Stewart Island is often omitted.

Since this study was carried out, I have endeavoured to provide opportunities for my students to explore maps. Both Pam and I have attempted to find maps that show all the islands in the Pacific in order to provide the students with a greater understanding of their homeland as well as learning about the geographical features of New Zealand.

More recently, a study on South America allowed the teachers in the syndicate to enlarge a map and cut out each country in the continent, creating a jigsaw map for a wall display. The students could now clearly see that South America is made up of many countries and this was much easier for them to recognise than attempting to separate New Zealand along provincial boundaries. 


\section{REFERENCES}

Acheson, G., \& Bednarz, S. (2003). Maps. Social Studies Review, 42 (2), 77-84.

Base, G. (2001). The Waterhole. Penguin Books: Australia.

Brown, M. (2000). Understanding, making and using maps. In S. C. Boyles

(Ed.) Putting research into practice in primary teaching and learning, (pp. 105114). London: David Fulton.

Buggey, J., \& Kracht, J. (1986). Geographic learning. Washington: National Council for the Social Studies.

Bulman. R., Cubey, P., Mitchell, L., \& Wilson, M. (2005). Creating continuity through literacy experiences at Wilton Playcentre. Early Childhood Folio 9, 10-17.

Chan, H. (2001). The key to maps. Victoria: National Geographic Society.

Croft, C, Dunn, K, \& Brown, G. (2001). Essential skills assessment: Information skills. Wellington: New Zealand Council For Educational Research.

Crooks, T., \& Flockton, L. (1996). Graphs, tables and maps assessment results 1995. Dunedin :Educational Assessment Research Unit University of Otago.

Crooks, T., \& Flockton, L. (2000). Graphs, tables and maps assessment results 1999. Dunedin: Educational Assessment Research Unit University of Otago.

Cutting, B., \& Cutting, J. (1998). The map book. Auckland. Wendy Pye.

Denscombe, M. (2000). The good research guide for small-scale social research projects. Buckingham: Open University Press.

Denzin, N., \& Lincoln, Y. (Eds) (1994). Handbook of qualitative research. Thousand Oaks: Sage.

Education Review Office. (2004). Quality of teaching in Years 4 and 8: Graphs, tables and maps. Wellington: Author.

Ellis. A.K. (1998). Teaching and learning elementary social studies (6 $6^{\text {th }}$ Edition). Boston: Allyn and Bacon.

Engeström, Y., Miettinen, R. \& Punamäki, R. (Eds.) (1999) Perspectives on activity theory. Cambridge: Cambridge University Press.

Flockton, L., \& Crooks, T. (1998). Social studies assessment results 1997. Dunedin: Educational Assessment Research Unit University of Otago.

Flockton, L., \& Crooks, T. (2000). Assessment results for Maori students 1999. Science, art, graphs, tables and maps. (National Education Monitoring Report 16). Wellington: Ministry of Education. 
Flockton, L., \& Crooks, T. (2002). Social studies assessment results 2001.

Dunedin: Educational Assessment Research Unit University of Otago.

Flockton, L., \& Crooks, T. (2002). Information skills assessment results 2001. (National Education Monitoring Report 21). Wellington: Ministry of Education.

Flockton, L., \& Crooks, T. (2004). Graphs, tables and maps assessment results 2003. Dunedin: Educational Assessment Research Unit. University of Otago.

Giorgis, C., Johnson, N.J., Bonomo, A, \& Colbert, C. (1999). Visual literacy. The Reading Teacher, 53 (2), 146-153.

Hardie, A. (2000). Young children's interpretations of terms for distant places. Unpublished research paper. Massey University.

Hardie, A. (2002). Young children's language and explanations of distant places. The New Zealand Journal of Social Studies, 10 (2) 22-27.

Haste, H. (1987). Growing into rules. In J. Bruner, \& H. Haste, (Eds.). Making sense: The child's construction of the world. (pp. 163-195). London: Methuen.

Haydon, J. (2002). Making a Map. Victoria: Nelson Thomson Learning.

Holland, P. (2004). What do young school children know about maps and where do they get their information? Paper presented at Annual Conference of the New Zealand Association for Research in Education, Wellington, November 24-26.

Johnson, S.A. (1999). Mapping the world. New York: Atheneum Books for Young Readers.

Lenhoff, R., \& Huber, L. (2000). Young children make maps! Young Children, 55 (5), 6-12.

Liben, L.S., \& Downs, R.M. (1993). Understanding person-space-map relations: Cartographic and developmental perspectives. Developmental Psychology, 29 (4), 739-752.

Liben, L.S., Kastens, K.A., \& Stevenson. L.M. (2002). Real-world knowledge through real-world maps: A developmental guide for navigating the educational terrain. Developmental Review, 22 (2), 267-322.

Liben, L.S., \& Yekel, C.A. (1996). Preschoolers' understanding of plan and oblique maps: The role of geometric and representational correspondence. Child Development, 67, 2780-2796.

McGee, J. (1993). Junior children can do mapping. The New Zealand Journal of Social Studies, 2 (1), 18-19.

McPherson, K. (2004). Visual literacy and school libraries. Teacher Librarian, 32 (2), 58-59.

Maxim, G. W. (1997). Developmentally appropriate map skills instruction. Childhood Education, 73, 206-212. 
Milne, A.A. (1990), Winnie-the-pooh. Aylesbury: Methuen.

Ministry of Education. (1992). Mathematics in the New Zealand curriculum. Wellington: Learning Media.

Ministry of Education. (1993). The New Zealand curriculum framework. Wellington: Learning Media.

Ministry of Education. (1997). Social Studies in the New Zealand curriculum. Wellington: Learning Media.

Muir, S. (1997). Why Johnny can't read maps. The New Zealand Journal of Social Studies, 6 (2), 26-28.

Palmer, J. (1994). Geography in the early years. New York: Routledge.

Panckhurst, F. (1989). The acquisition of cartography in preschool children. Unpublished PhD thesis Victoria University of Wellington.

Reid, N.A., Croft, C. A, \& Jackson, P. F. (1978). Progressive achievement Tests: Study skills. Wellington: New Zealand Council For Educational Research.

Rice, G.H. (1990). Teaching students to become discriminating map users. Social Education, 54 (6), 393-397.

Robertson, M., \& Gerber, R. (2000). The child's world: Triggers for learning. Melbourne: Australian Council for Educational Research.

Rowling, J.K. (1998). Harry Potter and the chamber of secrets. London: Bloomsbury.

Rowling, J.K. (1999). Harry Potter and the prisoner of Azkaban. London: Bloomsbury.

Segall, A. (2003). Maps as stories about the world. Social Studies and the Young Learner, 16 (1), 21-25.

Sowden, S., Stea, D., Blades, M., Spencer, C., \& Blaut, J.M. (1996). Mapping abilities of four-year-old children in York, England. Journal of Geography, 95, 107-111.

Swartz, E. (2002). Mapping all the way. Teaching Pre K-8, 33 (2), 64-65.

Vygotsky, L.S. (1978). Mind in Society: The development of higher order psychological processes. Cambridge: Harvard University Press.

Wendt, J. (1987). Blessing yams in Niue. Auckland: Longman Paul.

Whitefield, R. (1997). Charting a better course: Improving map use for the study of society and the environment. The New Zealand Journal of Social Studies, 6 (2), 20-25. 
Welton. D.A., \& Mallan J.T. (1996). Children and their world. Strategies for teaching Social Studies. (5 $5^{\text {th }}$ Edition). Boston: Houghton Mifflin.

Wiegand, P. (1992). Places in the primary school knowledge and understanding of places at key stages 1 and 2. London: Falmer.

Wiegand, P., \& Stiell, B. (1996). Lost continents? Children's understanding of the location and orientation of the earth's land masses. Educational Studies, 22 (3), 381-392.

\section{Picture Sources}

Burnett. J., \& Irons, C. (1997). Mathematics on the move. San Francisco: Mimosa.

Burnett. J., \& Irons. C. (1998). That's entertainment. San Francisco: Mimosa.

Crooks, T., \& Flockton, L. (1998). Information skills assessment results 1997. (National Education Monitoring Report 7). Wellington: Ministry of Education.

Evans, J., \& Osborne, C. (2003). Geography 1.4. Auckland: Pearson Education. 


\section{APPENDICES}

\section{Appendix A}

\section{Thesis Proposal}

\section{Research question}

What is young school children's understanding of maps?

\section{Introduction}

Although the use of maps is so widespread in our society, surprisingly little research appears to have been carried out into children's understanding of maps and their ability to use them. The National Education Monitoring Project (NEMP) has tested children's understanding of maps as a component of the New Zealand Curriculum Framework (1993). In particular, The Essential Information Skills (p. 17). There have been two reports from NEMP (Crooks \& Flockton, 1995, 1999) of results from a sample of Year 4 and Year 8 children. The commentaries accompanying the map related items do not suggest a high level of skill.

A study of a different kind was carried out by Panckhurst (1989), who studied a sample of New Zealand pre-school children's knowledge of maps. She was interested not only in what the children knew but how they came to know it. In the interviews with parents and children she explored the family and home as sources of map knowledge. Her work was guided by the socio-cultural theory of Vygotsky (1978) and maps were considered as artefacts culturally constructed and used in socially defined ways.

We now have some information on the level of success for the NEMP test items and information about the factors which seemed to influence the outcomes form the items, and we have information in the informal and environmental contexts such as floor maps in children's bedrooms or children's knowledge of route maps used by parents on car journeys. However, we know less about how to encourage map understanding and use.

With a number of varieties of maps, the choices for children are endless. There are route maps designed for navigational purposes. These are common in cars and on timetables as they display for the reader the route from point $A$ to point $B$. Topographical maps provide a more detailed view of an area. These include high and low points, mountains, rivers, roads and bush areas.

Atlas's put maps into one combined area to make it easier for people to find what they are looking for. Generally these maps focus on the world, but some have specific sections dedicated to the country they are printed in or relate to an area of the world such as the Pacific Region. Atlas's are usually found in classrooms and less commonly in the home.

In this study, children will use a variety of maps. Their skill in understanding them will be observed and form part of the outcome of this study. 


\section{Rationale}

Map skills are an important feature of everyday life. Being able to use a map is one of the information skills listed in the National Curriculum Framework (1993).

I have already carried out a small study in which I asked my class of Year 2 children to draw a map of New Zealand and to locate some major features.

Maps represent geographical features. What they represent can seldom be observed directly and their presentation involves culturally defined symbols and connections.

My study should be of interest to teachers, parents and educational professionals.

\section{Research Questions}

- What do young school children know about maps?

- Can young school children draw a map of New Zealand?

In a three week unit on route maps I will try to take the class through the Zone of Proximal Development to a high understanding of how maps work along with developing their knowledge of important geographical features of New Zealand.

\section{Theoretical Framework}

My research will inquire into how children understand maps and how they interpret them.

Vygotsky's (1978) well known definition of the zone of proximal development relates to this study. He states that "any learning a child encounters in school always has a previous history" p. 84. In this case the children's maps will be viewed as cultural artefacts. Alongside this will be the differing views and understandings that the children bring to the study, depending on their familiarity or experience with maps. They will be asked questions that explore their experiences with maps within the family, school and community.

It is possible to view map reading as part of the literacy process. Maxim (1997) stated that "learning to read and construct maps is much like the literacy process. Therefore, map skills instruction should begin with experiences that help develop fundamental background knowledge about the world" p. 2. He includes ideas such as observing the environment, photos and block play as ways to encourage children to develop their mapping skills Swartz (2002) also suggests these ideas and lists ways to get children creating maps and using them for themselves.

The students ideas about mapping will be based on their initial ideas and then their final understandings once a mapping unit has been taught. Separate data will be gathered from students in my own class during the unit. I will be considering whether maps are cultural artefacts.

\section{Methodology}

\section{Sample}

Eight children will be selected for interviewing. This group will comprise of 4 girls and 4 boys. Of these, 4 will be Maori and 4 from Pacific Nations. The children chosen for 
interviewing will come from a Year $3 \& 4$ classroom in a Decile 2 school in Porirua. None of the children, in the interview group, will be from the researcher's own class. Eight children will be randomly selected by putting all Maori and then all the Pacific Island children from the Year $3 \& 4$ group into a hat. The hat will contain smiley faces for the 4 required participants. There will be a sad face for the unsuccessful participants. From this selection, permission will be sought from their families. Should any family decline to participate, the draw will be repeated until all eight participants have been selected.

\section{Method}

For this project, I will conduct face-to-face interviews with the students involved prior to the introduction of a unit on Mapping. Artefacts will be gathered prior to the introduction of the unit and at the end in order to compare student knowledge. Included is a mind map showing the kind of information I am looking for.

Before embarking on the study, a pilot project will be carried out using students from the researchers own class. This will enable me to make any necessary changes to the questions I will be asking the sample group.

The students will be withdrawn from the classroom in order to carry out the interviews about their understanding of maps. The interviews will take place in an alcove off the main teaching space. The students will be asked to draw a map of New Zealand with specific geographical locations during the interview. The interview will be recorded to gather the student's understanding. This will be recorded in the form of a narrative. These interviews will take place two weeks prior to the introduction of a unit on mapping. Observations and anecdotal notes will be collected from the researchers own class during the unit. At the end of the unit the eight students will be withdrawn again to re draw their maps and to gather any other ideas they have about maps and to explore reasons why their understanding may have changed. The interviews will be recorded by tape recorder.

\section{Ethical Considerations}

The Ethical Guidelines set by NZARE and endorsed by Wellington College of Education and distributed in the MAST 500 course will be followed. Once approved, my proposal will be submitted to the ethics committee.

Prior to embarking on the interviews with the students, written and verbal permission will be sought from their parents/caregivers and the classroom teacher. Permission will also be sought from the Principal and Board of Trustees. Draft letters are attached.

\section{References}

Bohan, C.H. (2001). Begin where I am: Kindergarten geography. Social Studies and the Young Learner. Ser/Oct 2001. 14 (1), 20.

Bruner, J.S., \& Haste, H. (Eds.). (1987). Making Sense: The child's construction of the world. London: Methuen.

Crooks, T., \& Flockton, L. (1998). Information Skills Assessment Results 1997. National Education Monitoring Report 7. Wellington: Ministry of Education. 
Entwistle, N. (2002). Personal understanding and target understanding: Mapping influences on the outcomes of learning. The British Journal of Educational Psychology, Leicester; Sep 2002: Vol 72, 321-343.

Flockton, L., \& Crooks, T. (2002). Information Skills Assessment Results 2001. National Education Monitoring Report 21. Wellington: Ministry of Education.

Flockton, L., \& Crooks, T. (2000). Assessment Results for Maori Students 1999. Science, Art, Graphs, Tables and Maps. National Education Monitoring Report 16. Wellington: Ministry of Education.

Lenhoff, R., \& Huber, L. (2000). Young children make maps! Young Children. Sept 2000. 55 (5), 6.

Maxim, G. W. (1997). Developmentally appropriate map skills instruction. Childhood Education. Summer 1997, Vol. 73. 206.

Ministry of Education. (1993). The New Zealand Curriculum Framework. Wellington: Learning Media.

Ministry of Education. (1997). Social Studies in the New Zealand Curriculum. Wellington: Learning Media.

Panckhurst, F. (1989). The Acquisition of Cartography in Preschool Children. Unpublished PhD Thesis. Wellington: Victoria University.

Pickard, F., Granley, D., \& Christian, R. (1994) Our school's paths and places: an introduction to maps. Canadian Social Studies. Fall 1994, Vol. 29, 38.

Sowden, S., Stea, D., \& Blades, M. (1996). Mapping abilities of four-year-old children in York, England. Journal of Geography. May/June 1996, Vol 95, 107.

Swartz, E. (2002). Mapping All the Way. Teaching Pre K-8. 33 (2), 64.

Trifonoff, K.M. (1995). Going beyond location: thematic maps in the early elementary grades. Journal of Geography. March/April 1995. Vol 94, 368.

Vygotsky, L.S. (1978). Mind in Society: The development of higher order psychological processes. (Cole, M., John-Steiner, S., Scriber, S., \& Souberman, E. (Eds.). Cambridge: Harvard University Press. 


\section{Appendix B}

\section{BOT Letter}

$3^{\text {rd }}$ May 2003

Dear

I am enrolled in the Master of Education course at Wellington College of Education. This year I am undertaking a research project for my Thesis. My supervisors are Joanna Higgins and Geraldine McDonald.

My thesis involves finding out what the children in my syndicate know about maps and how well they know important geographical locations in New Zealand.

To undertake this research I need to interview a group of eight students. I would like the Board of Trustees permission to carry out this research.

The selected group of students will be interviewed in Rimu block to find out what they know about maps. They will be asked to draw a map and put specific places of interest on this. The interview will be recorded on tape and will take about half an hour. Everyone in the syndicate will be involved in unit on mapping. At the end of the unit I will need to interview the students again to see if they think any differently.

Anything they tell me will be strictly confidential. For the purposes of the study they will be given a different name. I will give the Board an account of my findings.

This study should be of interest to both parents and teachers.

If you have any further questions about the study, please feel free to ask and I will be happy to assist.

Thank you very much.

Paulette Holland 


\section{Appendix C}

\section{Parent Letter}

April 2003

I am enrolled in the Master of Education course at Wellington College of Education. This year I am undertaking a research project for my Thesis. My supervisors are Joanna Higgins and Geraldine McDonald.

My thesis involves finding out what children know about maps and how well they know important geographical locations in New Zealand.

To undertake this research I need to interview a group of students. I would like to include your child in my study.

The selected group of students will be interviewed in Rimu block to find out what they know about maps. They will be asked to draw a map and put specific places of interest on this. The interview will be recorded on tape and will take about half an hour. Everyone in the syndicate will be involved in unit on mapping. At the end of the unit I will need to interview the students again to see if they think any differently.

Anything they tell me will be strictly confidential. For the purposes of the study they will be given a different name. I will give you an account of my findings.

This study should be of interest to both parents and teachers.

Please return the attached form to school. I am looking forward to working on this study. I you have any questions about this I would be really pleased if you contacted me at school and l'd be happy to answer any questions.

Thank you very much.

Paulette Holland 


\section{Map Study Permission Form}

I give permission for

to be involved in Paulette

Holland's research.

- I understand that the information gathered by her will be strictly confidential and that no names will be used in the final report for her thesis. The same practice will be followed with any publications that arise from her research.

- I understand that I have the right to withdraw my child at any time.

- I understand that I have the right to see the written transcript of the interview.

- I understand that the information will be anonymous and kept in a safe place until the research is completed.

Signed

Date 


\section{Appendix D}

\section{Interview One Questions}

1. We are going to talk about maps. Can you show me the maps that are in this pile/ (have a selection of maps, tables and graphs)

2. Have you ever used a map before?

Show a route map and a topographical map.

Route map - what would you use this map for?

Topographical map - What would you use this map for?

3. Where would you find a map?

4. Do you have any maps at home? Tell me about these maps. Where are they kept?

5. Do you have a car? Are there any maps in the car? What are they used for?

6. Can you tell me what an atlas is?

7. Do you have an atlas? Is there one at home? At school?

8. Where would you find one?

9. Do you use a globe?

10. What is a map used for?

11. What is an atlas used for?

12. If your mother wanted to go somewhere and she didn't know exactly where to go, what should she do?

13. How would you find

- your street in your town?

- A city in another country?

- Find out how to get to someone's place?

14. If I told you I wanted to see some maps, could you find some for me? Where would you go?

15. What does reading a map mean?

16. Can you read a map? How do you do this?

17. Do you ever draw maps? What do you do this for? 
18. Draw a map of New Zealand. I'd like you to put these places on it.

- Wellington

- Auckland

- Christchurch

- Dunedin

- Lake Taupo

- Mount Taranaki

- Stewart Island

Tell me about your map. Explain why you have put these places here.

\section{Interview Two Questions}

1. What is a map used for?

2. Where would you find a map?

3. What does reading a map mean?

4. Can you read a map?

5. Can you tell me what an atlas is? What is it used for?

6. Do you have an atlas? Is there one at home? At school?

7. Where would you find and atlas?

8. Do you use a globe?

9. How would you find

- Your street in your town?

- A city in another town?

- How to get to someone's place?

10. Draw a map of New Zealand. I'd like you to put these places on it.

- Wellington

- Auckland

- Christchurch

- Dunedin

- Lake Taupo

- Mount Taranaki

- Stewart Island

11. Tell me about your map. Explain why you have put these places here. 


\section{Appendix E}

\section{Unit Overview}

Unit Title: $\quad$ Maps

\begin{tabular}{|l|l|}
\hline Class: Rimu Years 2-4 & $\begin{array}{l}\text { Date: Weeks 4-7 Term 3 } \\
2003\end{array}$ \\
\hline Unit Title: Maps & $\begin{array}{l}\text { Learning Area: Social } \\
\text { Studies }\end{array}$ \\
\hline Strand: Place and Environment & $\begin{array}{l}\text { Focus/Context: New } \\
\text { Zealand and significant } \\
\text { places/local area }\end{array}$ \\
\hline
\end{tabular}

\section{Achievement Objectives:}

Level One: How and why people record the important features of places and environments.

Level Two: How and why people describe places and environments in different ways.

Process/Functions: Levels 1-2

Inquiry - students will demonstrate skills as they collect, process, and communicate information about human society.

\section{Specific Learning Outcomes:}

Students will demonstrate knowledge and understandings when they:

1. Identify a place that is important and explain why it is important

2. Describe the ways in which people can record features of places and environments (mapping)

3. Describe how people make use of descriptions of places and environments (maps for directions)

4. Explain why people record descriptions of places and environments in different ways

5. Explain why people choose to record particular features of places and environments.

\section{Essential Skills Focus:}

$\begin{array}{ll}\text { Communication } 4 & \text { Self-Management and Competitive Numeracy } 4 \\ \text { Social and Cooperative } 4 & \text { Physical } \\ \text { Information } 4 & \text { Work and Study } 4 \\ \text { Problem Solving } 4 & \end{array}$

\begin{tabular}{|l|l|l|l|}
\hline Cross Curriculum Links: & \multicolumn{2}{|l|}{ Achievement Objectives } \\
\hline Area & \multicolumn{1}{|c|}{ Strand } & $\begin{array}{l}\text { Level 1 } \\
\& 2\end{array}$ & Direction and length \\
\hline Mathematics & Oral Language & $\begin{array}{l}\text { Level 1 } \\
\& 2\end{array}$ & $\begin{array}{l}\text { Discuss occupations. } \\
\text { Interview others } \\
\text { Present ideas to a } \\
\text { group }\end{array}$ \\
\hline English & $\begin{array}{l}\text { Assessment Criteria: } \\
\text { Key Resources: }\end{array}$ & \multicolumn{2}{|l}{} \\
$\begin{array}{l}\text { National Library Books } \\
\text { Community } \\
\text { Newspapers } \\
\text { Atlas }\end{array}$ & \multicolumn{2}{|l}{} \\
\hline
\end{tabular}


Globe

Maps

Internet Map sites - wises.co.nz \& Terralink

Teaching/Learning Context and Sequence:

- Get students to draw a map of NZ at the start of the unit to see what they know. Include Auckland, Wellington, Christchurch and Dunedin, Mount Taranaki, Lake Taupo and Stewart Island.

- Introduce NZ and its location in the world.

- Map routes to office or areas in the school.

- Maps routes to home - possibly a homework task.

- Map the route to important features in the neighbourhood.

- Investigate where their family come from and use maps of the Pacific.

- Use Atlases and Globes.

- Discuss the language associated with maps.

\section{Possible learning experiences for unit:}

- Children design a map for getting to their house

- Locate other areas in the world

- Link the local area and its location in the Wellington region

- Investigate the various types of maps and where to find them

- Use language - co-ordinates, longitude and latitude

Prior to the unit - Draw a map showing how to get from school to the park.

Repeat at the end to see what changes the students would make. Question why they would make these changes and record their ideas.

\section{Unit Evaluation:}

